\title{
A theory of phenomenal geometry and its applications
}

\author{
WALTER C. GOGEL \\ University of California, Santa Barbara, California
}

\begin{abstract}
The geometry of perceived space (phenomenal geometry) is specified in terms of three basic factors: the perception of direction, the perception of distance or depth, and the perception of the observer's own position or motion. The apparent spatial locations of stimulus points resulting from these three factors thereupon determine the derived perceptions of size, orientation, shape, and motion. Phenomenal geometry is expected to apply to both veridical and illusory perceptions. It is applied here to explain a number of representative illusions, including the illusory rotation of an inverted mask (Gregory, 1970), a trapezoidal window (Ames, 1952), and any single or multiple point stimuli in which errors in one or more of the three basic factors are present. It is concluded from phenomenal geometry that the size-distance and motion-distance invariance hypotheses are special cases of the head motion paradigm, and that proposed explanations in terms of compensation, expectation, or logical processes often are unnecessary for predicting responses to single or multiple stimuli involving head or stimulus motion. Two hypotheses are identified in applying phenomenal geometry. It is assumed that the perceptual localization of stimulus points determines the same derived perceptions, regardless of the source of perceptual information supporting the localizations. This assumption of cue equivalence or cue substitution provides considerable parsimony to the geometry. Also, it is assumed that the perceptions specified by the geometry are internally consistent. Departures from this internal consistency, such as those which occur in the size-distance paradox, are considered to often reflect the intrusion of nonperceptual (cognitive) processes into the responses. Some theoretical implications of this analysis of phenomenal geometry are discussed.
\end{abstract}

An observer, upon viewing a three-dimensional visual scene, acquires an internal spatial representation, which can then contribute to or determine responses to that scene. This internal representation, usually supported by sensory information, is an instance of phenomenal space. The geometrical description of this phenomenal space will be called phenomenal geometry. The purpose of this paper is to summarize and provide examples of a theory of phenomenal geometry, various portions of which have been described in previous articles (Gogel, 1981a, 1982, 1983; Gogel \& DaSilva, 1987a, 1987b; Gogel \& Tietz, 1974). Two hypotheses underlying the theory and some theoretical consequences of the theory will be discussed. It will be shown that this theory can explain a number of representative illusions, obviating the need to describe these phenomena in other, usually more complex, terms. The theory is expected to apply whether the observer and/or the stimulus is physically moving or physically stationary and whether the perceptions are accurate or are in error.

The preparation of this article was supported by Research Grant MH 39457 from the United States National Institute of Mental Health. I thank John M. Foley, Tarow Indow, Michael T. Swanston, and two anonymous reviewers for their helpful comments on an earlier draft of this manuscript. Correspondence should be addressed to Walter C. Gogel, Department of Psychology, University of California, Santa Barbara, CA 93106
Examples of a partial phenomenal geometry are provided by hypotheses of invariance. These are equations that express the interrelation of several perceptions. For example, the size-distance invariance hypothesis and the shape-slant invariance hypothesis state that a given retinal (proximal) stimulus specifies a ratio of two perceptions-perceived size and perceived distance in the one case and perceived shape and perceived slant in the other. Such equations contain terms for proximal stimuli (retinal size and retinal shape in the above examples), as well as perceptual terms. A complete phenomenal geometry that would reflect all aspects of the phenomenal world, however, would involve only perceptual terms. Such a complete phenomenal geometry, if it is to be general, must be able to derive more complex perceptions from the perceptual variables postulated to be basic. The basic variables of the theory described here are (1) perceived direction, (2) perceived distance or depth, and (3) the observer's awareness (perception) of his or her own position or motion. This theory asserts that these three basic perceptual variables together determine the perceived positions of points in perceptual threedimensional space. Numbers of such points at different apparent spatial locations, or movement between these different apparent locations, provide the derived perceptions of size, shape, orientation, and motion. It is useful experimentally that each of the three basic variables can be manipulated independently of the others. For exam- 
ple, the position of the observer and the stimulus can be changed simultaneously in perceived space, keeping the perceived direction and perceived distance of the stimulus from the observer constant. Or, the accommodation or convergence to an object can be changed so as to change its apparent distance while leaving its perceived direction and the perceived position of the observer unmodified. The theory, however, does not assert that perceived direction, perceived distance, and the perception of self-motion or -position necessarily are independent of the matrix of stimuli in which the point is embedded. It is proposed, instead, that when such context interactions occur, their effects on perception can be identified as modifications of perceived direction, perceived distance, and/or the observer's perception of his or her own location or motion.

\section{APPLICATION OF PHENOMENAL GEOMETRY TO A SINGLE TEST OBJECT}

Considerable evidence for the validity of the theory of phenomenal geometry is found in a method of measuring apparent distance called the head motion procedure or head motion paradigm (see Gogel, 1981a, for a review). An application of this procedure consists of using the illusory motion of the test object (or the nulling of this illusory motion by an opposite physical motion) that can occur concomitantly with a lateral motion of the head, to provide an indirect measure of the perceived distance of the test object. The kind of situation in which this is accomplished is shown in Figure 1A. In Figure 1, and throughout this article (except in Figure 3), the open objects (e.g., open circles in Figures $1 \mathrm{~A}$ and $1 \mathrm{~B}$ and open rectangles in Figure 1C) and primed letters identify perceived characteristics of the test objects. Filled circles or filled rectangles and unprimed letters identify physical characteristics of the test objects. Figure 1A represents a situation in which a stationary test point of light at the physical distance $D_{\mathrm{m}}$ from the observer is viewed as the observer's head moves left and right repetitively through a perceived lateral extent, $K^{\prime}$, which may or may not be the same as the physical motion $K$ of the head. If the test point is made to appear nearer, $D_{\mathrm{n}}^{\prime}$, or farther, $D_{\mathrm{f}}^{\prime}$, than its physical distance $D_{\mathrm{m}}$ (perhaps by changing the convergence to the test point using prisms), the point will appear to move concomitantly with the head in the same direction as the head motion or opposite to the direction of the head motion, respectively. The physical distance, $D_{\mathrm{m}}$, of the physically stationary test point is the distance around which the direction from the observer to the test point intersects or pivots as the head is moved laterally. This is called the pivot distance, and it is labeled $D_{\mathrm{p}}$ in Figure 1A. It should be noted, however, that if the test point had been physically moved laterally, concomitantly with the head, in the same direction as, or opposite to, the physical direction of the head motion, the pivot distance would have been greater than or less than the physical distance of the test point, respectively (also see Gogel, 1982, Figure 1). As predicted from phenomenal geometry, for a given perceived motion of the head, both the perceived distance and perceived direction of the test object, with the latter modifiable by changing the pivot distance to the test object, will change the apparent concomitant motion of the test object. The equation relating the perceived (illusory) motion ( $\left.W^{\prime}\right)$ of the test object, the

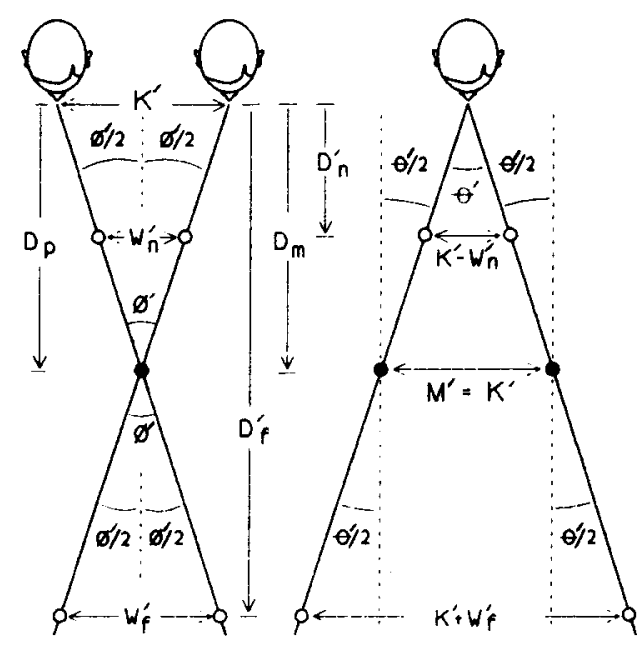

A
B

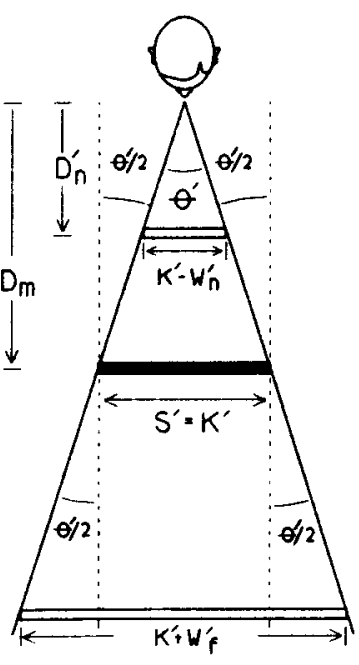

C

Figure 1. As is illustrated in Figures 1B and 1C, respectively, the apparent size-distance $\left[S^{\prime}=2 D^{\prime} \tan \left(\theta^{\prime} / 2\right)\right]$ and the apparent motion-distance invariance hypothesis $\left[M^{\prime}=2 D^{\prime}\right.$ $\left.\tan \left(\theta^{\prime} / 2\right)\right]$ are predicted from the head motion paradigm $\left[W^{\prime}=K^{\prime}-2 D^{\prime} \tan \left(\phi^{\prime} / 2\right)\right]$ shown in Figure $1 \mathrm{~A}$, in this case for the condition in which $\phi^{\prime}=\theta^{\prime}$. 
perceived lateral motion $\left(K^{\prime}\right)$ of the head, the change in the perceived direction $\left(\phi^{\prime}\right)$ of the point relative to the head, and the perceived distance $\left(D^{\prime}\right)$ of the test point is

$$
W^{\prime}=K^{\prime}-2 D^{\prime} \tan \left(\phi^{\prime} / 2\right) \text {. }
$$

If $\tan \phi^{\prime}=\tan \phi$, and if $K^{\prime}=K$, then Equation 1 can be written as

$$
W^{\prime}=K\left(1-D^{\prime} / D_{\mathrm{p}}\right),
$$

where $D_{\mathrm{p}}$ is the pivot distance and $\tan (\phi / 2)=K /\left(2 D_{\mathrm{p}}\right)$ (see Gogel, 1983). The perception of lateral motion, $W^{\prime}$, concomitant with the lateral motion of the head is positive if the test object is perceived to move in the same direction as the lateral motion of the head, and it is negative if the test object is perceived to move opposite to the direction of the lateral motion of the head. Equation 2 is called the apparent distance, pivot distance hypothesis (Gogel, 1982). It can be applied only if it is assumed that $\tan \phi^{\prime}=\tan \phi$ and $K^{\prime}=K$. Equation 1, however, because it is an instance of complete phenomenal geometry, does not require these assumptions.

Figure 1B is similar to Figure $1 \mathrm{~A}$, except that the head is perceived to be stationary (perhaps because it is stationary) and the perceived extent of lateral motion of the stimulus point is $M^{\prime}$. It is assumed that the perceived motion of the point at $D_{\mathrm{m}}$ is $K^{\prime}$, which is the same at the perceived motion of the head in Figure $1 \mathrm{~A}$ (that is, $M^{\prime}$ at $D_{\mathrm{m}}=K^{\prime}$ ). In this case, it is clear that the change in perceived direction $\theta^{\prime}$ in Figure 1B equals $\phi^{\prime}$ in Figure 1A. It follows that, if the test point in Figure $1 \mathrm{~B}$ is perceived at $D_{\mathrm{n}}^{\prime}$ or $D_{\mathrm{f}}^{\prime}$, its perceived motion $M^{\prime}$ at these perceived distances will equal $K^{\prime}-W_{\mathrm{n}}^{\prime}$ and $K^{\prime}+W_{\mathrm{f}}^{\prime}$, respectively, where $W_{\mathrm{n}}^{\prime}$ and $W_{\mathrm{f}}^{\prime}$ in Figure $1 \mathrm{~B}$ are the same as in Figure 1A. The situation in Figure 1A is an instance of the head motion paradigm; that in Figure $1 B$ is an instance of what can be called the motion-distance invariance hypothesis (MDIH). Evidence for the validity of the MDIH is found in experiments by Rock, Hill, and Fineman (1968) and by Wist, Diener, and Dichgans (1976). An equation expressing the MDIH as a partial perceptual equation replacing $\theta^{\prime} / 2$ by $\theta / 2$ in Figure $1 \mathrm{~B}$ is

$$
M^{\prime}=2 D^{\prime} \tan (\theta / 2) \text {. }
$$

An equation expressing the MDIH in completely perceptual terms consistent with Figure $1 \mathrm{~B}$ is

$$
M^{\prime}=2 D^{\prime} \tan \left(\theta^{\prime} / 2\right) \text {. }
$$

Figure $1 \mathrm{C}$ represents an instance of the size-distance invariance hypothesis (SDIH) in which a laterally extended test object at a physical distance $D_{\mathrm{m}}$ from the observer has a perceived width $\left(S^{\prime}\right)$ equal to the $K^{\prime}$ in Figure $1 \mathrm{~A}$. Whenever the test object is perceived at $D_{\mathrm{n}}^{\prime}$ or $D_{\mathrm{f}}^{\prime}$, it is expected from the SDIH that its perceived width $S^{\prime}$ will equal $K^{\prime}-W_{\mathrm{n}}^{\prime}$ or $K^{\prime}+W_{\mathrm{f}}^{\prime}$, respectively. A partially perceptual equation replacing $\theta^{\prime} / 2$ by $\theta / 2$ in Figure 1C, which often is used to express the SDIH, is

$$
S^{\prime}=2 D^{\prime} \tan (\theta / 2) \text {. }
$$

The equation for the SDIH, expressed in completely perceptual terms consistent with Figure 1C (see Gogel \& DaSilva, 1987b; McCready, 1985, 1986), is

$$
S^{\prime}=2 D^{\prime} \tan \left(\theta^{\prime} / 2\right) \text {. }
$$

Since $\theta^{\prime}$ in Figure $1 \mathrm{~B}$ is equal to $\theta^{\prime}$ in Figure $1 \mathrm{C}$ and equal to $\phi^{\prime}$ in Figure $1 \mathrm{~A}$, it follows that

$$
M^{\prime}=S^{\prime}=K^{\prime}-W^{\prime} \text {. }
$$

Several aspects of Figure 1 are of particular interest for the present discussion. One is that the relations expressed by Equations 1, 4, 6, and 7 occur entirely between perceptual variables. This means that whenever any of the perceptual variables $K^{\prime}, \phi^{\prime}, \theta^{\prime}$, or $D^{\prime}$ do not equal the corresponding physical variables $K, \phi, \theta$, or $D$, it is the perceptual and not the physical values that are considered by the theory of phenomenal geometry to determine $W^{\prime}$, $M^{\prime}$, and $S^{\prime}$. Instances in which $K^{\prime}$ does not equal $K$ include an observer's underperception of motion when seated in a moving vehicle or the perception of self-motion (vection) that occurs when a stationary observer views a large field of moving stripes (Wist, Diener, Dichgans, $\&$ Brandt, 1975). Substantial errors in the perception of visual direction can result from prolonged viewing of an object moving concomitantly with a lateral motion of the head (Hay, 1968; Hay \& Goldsmith, 1973; Tietz \& Gogel, 1978; Wallach \& Floor, 1970). However, two studies in which the head motion paradigm was used with less continuous viewing did not reveal significant errors in this variable (Gogel, 1982; Gogel \& Tietz, 1979). Conditions under which $D^{\prime}$ is not equal to $D$ can occur frequently in both natural and experimental situations. This can occur, for example, as a function of the distance of fixation (Gogel, 1979a; Gogel \& Tietz, 1977), or as a consequence of modifying oculomotor cues of distance with physical distance constant (Gogel \& Tietz, 1979). Experiments involving the latter condition have been used extensively to examine the validity of Equation 2 (Gogel, 1983).

An aspect of special interest regarding Figure 1 is that the MDIH (Figure 1B) and the variation on the SDIH known as Emmert's law (Figure 1C) are special cases of the head motion paradigm applicable to a stationary head. It follows that phenomenal geometry expressed in terms of perceived distance, of perceived direction or changes in perceived direction (perceived visual angle), and of the observer's perception of the self as stationary or moving can explain phenomena involving either a stationary or moving observer viewing either a moving or a stationary stimulus. The expression of the head motion paradigm in completely perceptual terms (Equation 1) implies that the MDIH (Equation 4) and SDIH (Equation 6) also must contain only perceptual variables. The latter equation is in agreement with McCready's formulation (McCready, 1965,1985 ) of the SDIH in terms of perceived visual angle rather than physical visual angle. It may not seem particularly surprising that perceived direction and perceived distance, together with the contribution of the observer's perception of self-motion or -position, can pro- 
vide perceptual localization in space and thus can provide a common explanation for a variety of spatial phenomena. As will be discussed, however, this approach can explain phenomena that have customarily been understood in terms of higher order factors, such as cognition, compensation, or expectation.

\section{Evidence Regarding Figure 1}

There is evidence from three studies that $W^{\prime}, M^{\prime}$, or $S^{\prime}$ can provide similar or highly correlated measures of $D^{\prime}$ and that they thus are likely to involve the same processes. ${ }^{1}$ In one study (Gogel, 1979a), $D^{\prime}$ was measured by the physical size adjusted to achieve a particular perceived size, using a variation of the SDIH (Equation 5) to compute $D^{\prime}$. Also, $D^{\prime}$ was computed from $W^{\prime}$, using the head motion procedure and a variation of Equation 2 . The two measures of $D^{\prime}$ varied in the same direction, although the measure using the SDIH gave larger values of $D^{\prime}$ than those obtained from the head motion procedure. In a later study (Gogel, Loomis, Newman, \& Sharkey, 1985), measures of $D^{\prime}$ from applying the head motion procedure and from size adjustments using the SDIH were obtained. As expected, both measures increased with increases in $D^{\prime}$, but again there was a tendency for the measures obtained from the SDIH to be larger than those from the head motion procedure. The correlation between the average values resulting from the two kinds of measures in that study was very high $(r=$ 0.981 ). A third study, in which methodological differences were minimized in obtaining measures of $D^{\prime}$ calculated from $W^{\prime}$ and $M^{\prime}$, was done by Gogel and Tietz (1979). The conditions used in that study are illustrated in Figure 2. The situations represented in Figure 2A are basically the same as those of Figure $1 \mathrm{~A}$. In Figure 2A, a physically stationary test point at the physical distance $D$ appeared to move laterally in the direction of the head motion when it was perceived at $D_{\mathrm{n}}^{\prime}$ and against the head motion when it was perceived at $D_{\mathrm{f}}^{\prime}$. Figure $2 \mathrm{~B}$ illustrates the same conditions as those in Figure $2 \mathrm{~A}$, except that the test point, rather than remaining physically stationary, physically moved vertically through a distance $M$, concomitant with the lateral motion of the head. In this case, the illusory perceived horizontal motion $\left(W^{\prime}\right)$ vectored with the vertical perceived motion $\left(M^{\prime}\right)$ resulting from the physical vertical motion $(M)$ to produce an apparently tilted path of motion of the test point $\alpha_{\mathrm{n}}^{\prime}$ at $D_{\mathrm{n}}^{\prime}$ and $\alpha_{\mathrm{f}}^{\prime}$ at $D_{\mathrm{f}}^{\prime}$. The different values of $M^{\prime}$, illustrated in Figure 2B, resulting from the different values of $D^{\prime}$ are consistent with those expected from the MDIH. Since both $M^{\prime}$ and $W^{\prime}$ determined $\alpha^{\prime}$, measures of perceived distance $\left(D^{\prime}\right)$ obtained from $\alpha^{\prime}$ would equal those obtained from $W^{\prime}$ (for the same perceived distance $D_{\mathrm{n}}^{\prime}$ or $D_{\mathrm{f}}^{\prime}$ ) only if the MDIH illustrated in Figure 2B is a special case of the head motion paradigm. In other words, the measurement of $D^{\prime}$ from $\alpha^{\prime}$ in the situation of Figure 2B involves the simultaneous solution of Equations 2 and 3 (computed in that study using the assumptions that $\phi^{\prime}=\phi, \theta^{\prime}=\theta$, and $K^{\prime}$ $=K$ ). If, in Figure 2, the computed values of $D^{\prime}$ from $\alpha^{\prime}$ and $D^{\prime}$ from $W^{\prime}$ are the same or are highly related, it is likely that the same or similar processes are involved in both the head motion paradigm and the MDIH (or $\mathrm{SDIH}$ ). The average $D^{\prime}$ results from the experiment are shown in Figure 3 for two different methods of measuring $W^{\prime}$ and $\alpha^{\prime}$. In one of these, the comparison method, the observer adjusted the separation between posts or the tilt of a rotatable rod to be the same as the perceived horizontal motion $\left(W^{\prime}\right)$ or perceived path of tilt $\left(\alpha^{\prime}\right)$ of the display previously seen with a moving head. In the other, the duplication method, the observer, with the head stationary, duplicated on the display monitor the lateral motion $\left(W^{\prime}\right)$ or tilt $\left(\alpha^{\prime}\right)$ of the path of motion previously seen with a moving head. Three physical distances, 30.0, 55.9, or $96.4 \mathrm{~cm}$, were used with either monocular or binocular observation of the experimental display. The dashed

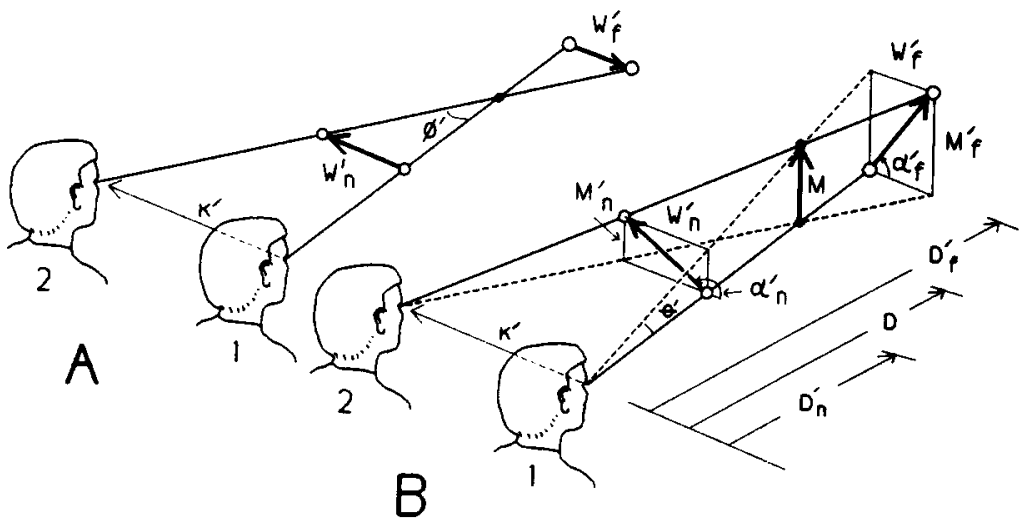

Figure 2. Drawings illustrating the vector addition of perceived horizontal motion $\left(W^{\prime}\right)$ and perceived vertical motion $\left(M^{\prime}\right)$, concomitant with a perceived horizontal motion $\left(K^{\prime}\right)$ of the head, so as to determine the perceived tilt $\left(\alpha^{\prime}\right)$ of the apparent path of motion of the test point. Modified from "A Comparison of Oculomotor and Motion Parallax Cues of Egocentric Distance" by W. C. Gogel and J. D. Tietz, 1979, Vision Research, 19, p. 1162. Copyright 1979 by Pergamon Press. Adapted by permission. 


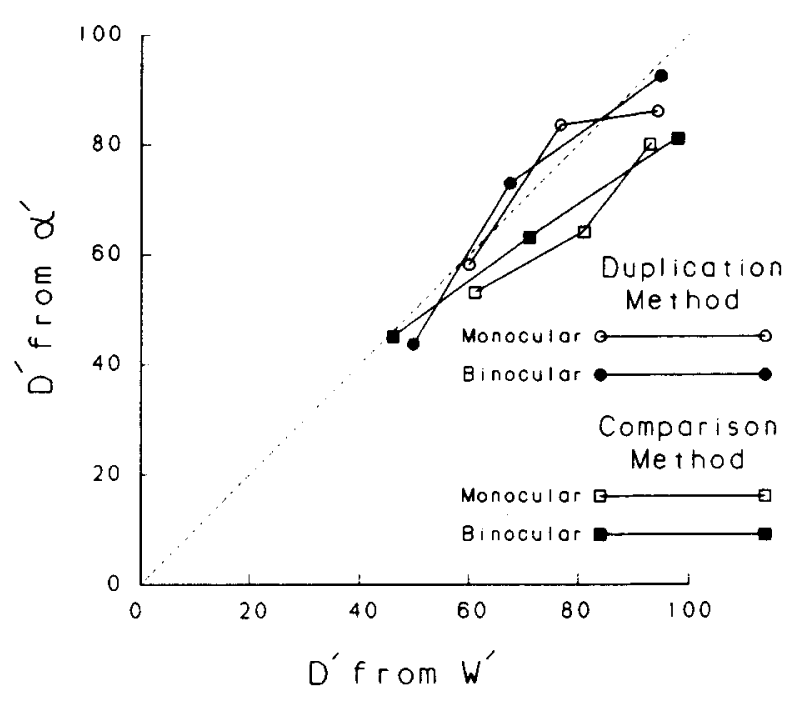

Figure 3. The average results of computing the perceived distance $D^{\prime}$ of the test point illustrated in Figure 2 from values of $W^{\prime}$ and $\alpha^{\prime}$ obtained using a comparison and duplication method of measurement and monocular or binocular vision.

line in Figure 3 is the result expected if the $D^{\prime}$ values measured from $W^{\prime}$ were identical to the $D^{\prime}$ values measured from $\alpha^{\prime}$. The obtained average values are closer to the dashed line for the duplication method than for the comparison method. For either the comparison or duplication method, however, the results clearly show that $D^{\prime}$ from $W^{\prime}$ and $D^{\prime}$ from $\alpha^{\prime}$ are highly related. Since the same $D^{\prime}$ values were being measured by the duplication and comparison methods, the differences that remain between the data from these two methods probably reflect the sensitivity of measurement of $D^{\prime}$ to procedural differences. Thus, there is both logical and experimental evidence to support the assertion that the MDIH and the SDIH are special cases of the head motion paradigm. This conclusion also suggests that the perception of extent obtained with a stationary head is a special case of that obtained with a moving head and that a theory of either must explain both.

\section{Other Explanations of the Perceptions Illustrated by Figure 1}

In a study by Post and Leibowitz (1982), it was concluded that the perception of illusory motion associated with a stationary target and a laterally moving head (Figure 1A) is a consequence of two eye movement systems. As the head is moved laterally, one, the older system, acts to maintain fixation on the test object by means of the vestibulo-ocular reflex (VOR), in which the gain of the reflex varies with the convergence of the eyes to the test object. If an error in convergence occurs, perhaps because of a tendency for the convergence to be displaced in the direction of its resting state, the eyes will tend to turn too much or too little as the head is moved. To counter this potential or actual loss of fixation, pursuit eye mo- tions are initiated, which then determine the direction and amount of perceived illusory motion of the test object concomitant with the motion of the head. This theory will here be called the VOR theory.

A limitation of the VOR theory is that it is incomplete. Pursuit eye movements can specify changes in the angular direction and extent of perceived motion, but they cannot by themselves determine a linear (metric) extent of perceived motion, such as a perception that the test object is moving laterally for a distance of $2 \mathrm{ft}$ or 2 in. For a linear perception, a perception of distance in addition to the angular information is needed. It is clear, however, that the perception of illusory motion concomitant with head motion, as illustrated in Figure 1A, is linear. In a variety of experiments (Gogel, 1981a), observers had no difficulty in indicating linear judgments of the lateral extent of the perceived illusory motion, which they accomplished usually by tactually adjusting the lateral separation of comparison rods. The inability of the VOR theory to specify the linear extent of illusory motion is indicated in Figure 4, in which the perception of angular motion $\delta^{\prime}$ from VOR theory is compared with $W^{\prime}$ from the head motion procedure, as the head moves from Position 1 to Position 2. Suppose that in Figure 4 prisms are used to change the convergence distance $\left(D_{c}\right)$ of the test point (physically stationary at $D_{\mathrm{m}}$ ) to a distance nearer than its physical distance (Figure 4A) or farther than its physical distance (Figure 4B). Also, suppose for convenience that, as a result of this change in convergence, the perceived distance of the test point is at $D_{n}^{\prime}$ in Figure 4A and at $D_{\mathrm{f}}^{\prime}$ in Figure 4B. The apparent angular concomitant motion expected from the angular pur-
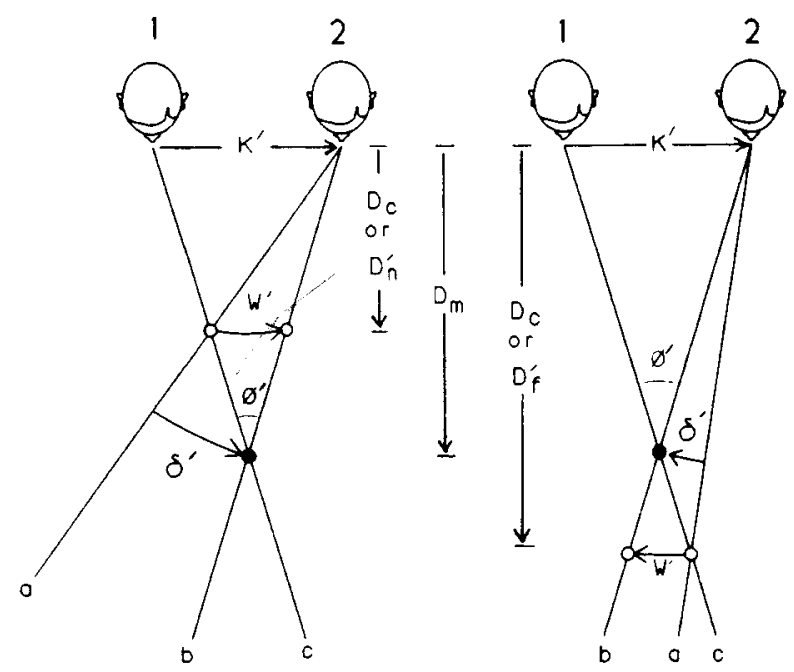

A

Figure 4. A comparison of the predictions from the vestibulo-ocular reflex theory, and from the head motion paradigm theory for the perceived motion ( $\delta^{\prime}$ or $W^{\prime}$, respectively) of a single, physically stationary test point, apparently moving concomitantly with a latera] motion of the head. 
suit eye movement, as postulated by VOR theory, is $\delta^{\prime}$, which is added because the convergence and physical distance of the test point differ. If the arrow indicating $\delta^{\prime}$ is to represent the perception of illusory motion concomitant with the motion of the head, it is unclear where it should be drawn. In their Figure 1, Post and Leibowitz (1982) place the arrow at the physical distance of the test point $D_{\mathrm{m}}$ rather than, as might be expected from the convergence cue of distance, at $D_{\mathrm{n}}^{\prime}$ or $D_{\mathrm{f}}^{\prime}$. If the arrow designating angle $\delta^{\prime}$ were placed at $D_{\mathrm{n}}^{\prime}$ or $D_{\mathrm{f}}^{\prime}$, it is evident from Figure 4 that the magnitude and direction of the illusory linear motion could depend upon apparent distance, as is expected from the head motion paradigm but is unspecified from VOR theory. For the perceived linear motion of a single test point viewed with a lateral motion of the head, both the VOR and the theory advocated in this paper could apply equally, but only if VOR theory incorporated the factor of perceived distance. Perhaps the possibility should be considered that the magnitude of the vestibuloocular reflex is determined by the perceived distance of the test point rather than by convergence per se,

In the situations of Figures $2 \mathrm{~A}$ and $2 \mathrm{~B}$, the $D^{\prime}$ values computed from $W^{\prime}$ and $\alpha^{\prime}$, particularly when using the duplication procedure, are very similar (see Figure 3). But, in the situation of Figure 2B, the VOR was not involved in the component of perceived motion $\left(M^{\prime}\right)$ produced by the vertical motion of the test point. However, the high correlations between $D^{\prime}$ measures obtained from the head motion procedure alone (Figure 2A), presumably involving the VOR, and the added MDIH situation (Figure 2B), not involving the VOR, suggests that the relation between convergence and the VOR added little that was not also available from perceived distance. In the case of the illusory motion of a single, physically stationary test object viewed with a laterally moving head, it is often difficult to distinguish the possible contributions of these two theories. This is because convergence can determine both the perceived distance of the test object consistent with the head motion paradigm and the gain of the VOR consistent with VOR theory.

Leibowitz (1971), Leibowitz and Moore (1966), and Leibowitz, Shiina, and Hennessy (1972) have interpreted the size perception obtained at near distances in terms of the reafference principle and oculomotor adjustments, instead of perceived distance, as asserted by the SDIH. According to these authors, it is expected from reafference theory that the oculomotor adjustments initiated by efference commands become associated with the image changes expected on the retina when an object of constant physical size is moved to a different distance from the observer. If the change in the size of the retinal image is consistent with that expected from the efference command, the efference and reafference will be in agreement and the apparent size of the object will remain constant (perfect size constancy). Conversely, if the visual angle of the object is kept constant, the lack of change in retinal size with changes in efference will result in the perceived size decreasing with the increase in the magni- tude of the oculomotor adjustments according to the reafference principle. This result, using geometrical stimuli, was obtained in the above studies by Leibowitz and his associates. Although such results also would be expected from the SDIH, the reafference interpretation avoids the concept of perceived distance. But, as noted by the authors, the reafference explanation can apply only to the near distances over which oculomotor adjustments are effective. A different explanation must be used to explain the application of the SDIH to distances greater than several meters. Nor can the reafference explanation apply to the head motion procedure. Thus, an additional advantage of the theory of phenomenal geometry, unlike the VOR explanation of $W^{\prime}$ in Figure $1 \mathrm{~A}$ or the reafference principle explanation of $S^{\prime}$ in Figure $1 \mathrm{C}$, is that the same theory applies to all of the situations illustrated in Figure 1.

\section{APPLICATION OF PHENOMENAL GEOMETRY TO MULTIPLE OBJECTS OR TO OBJECTS EXTENDED IN DEPTH}

The above discussion of applications of phenomenal geometry have been limited to a single test object. Phenomenal geometry is also expected to apply to multiple objects located at different perceived distances or to objects extended in depth. Consider the phenomenon of the illusory direction of rotation of Ames's trapezoidal window, illustrated in Figure 5. This drawing represents top views of the physical (solid lines and filled circles) and perceived (dashed lines and open circles) orientations of the trapezoidal window. In the situation shown, the small end of the window $(n)$ is physically closer to the observer than is the large end $(f)$, but it always appears $\left(n^{\prime}\right)$ to be the more distant end. When the window physically rotates counterclockwise from $n_{1} f_{1}$ to $n_{2} f_{2}$, it appears to rotate clockwise from $n_{1}^{\prime} f_{1}^{\prime}$ to $n_{2}^{\prime} f_{2}^{\prime}$. The explanation of this illusion that Ames (1952) proposed is consistent with the "best bet" hypothesis of transactional theory. It is assumed by the "best bet" hypothesis that two factors are responsible for the illusory perception of direction of rotation in the situation illustrated in Figure 5. One is the illusory perception of the depth orientation of the window. The other is the decrease in the overall angular size of the window $\left(\alpha_{1}>\alpha_{2}\right)$ as the window physically rotates counterclockwise. The logical conclusion for the observers from these two sources of information is that the window is rotating clockwise. According to the present theory of phenomenal geometry, however, logic is not required. If the observer correctly senses his or her head as stationary, the perceptual information provided by the perspective cue to the distance of each end of the window, together with substantially accurate perceptions of the directions to these ends, localizes the position of the window in perceived space at any instant of time and is sufficient to explain the illusory rotation. The logical consequence of the change in the visual angle of the window is superfluous. There is no need to postulate a "best bet" 


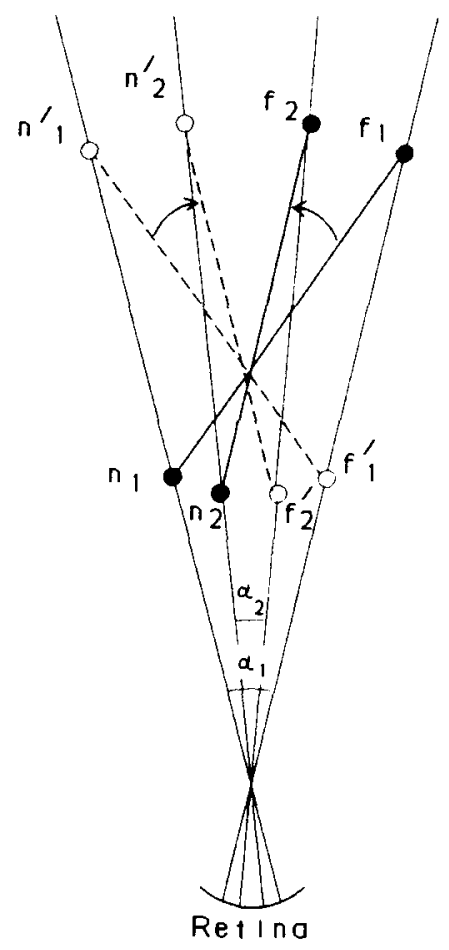

Figure 5. A top-view drawing illustrating a perceived rotation of an example of Ames's trapezoidal window in a direction opposite to that of its physical rotation. This illusory direction of rotation is consistent with the correct perception of the relative directions of the parts of the window but an incorrect perception of their relative distances as produced by the illusory perspective of the window. The solid circles and nonprimed notations represent the physical positions of the two ends of the window as the window physically rotates counterclockwise from $n_{1} f_{1}$ to $n_{2} f_{2}$. The open circles and primed notations represent the apparent positions of the two ends of the window, which is perceived to rotate clockwise from $n_{i}^{\prime} f_{i}^{\prime}$ to $n_{2}^{\prime} f_{2}^{\prime}$. The physical visual angles subtended by the window are $\alpha_{1}$ at $n_{1} f_{1}$ and $\alpha_{2}$ at $n_{2} f_{2}$.

process. In addition, the same factors of perceived distance and perceived direction are expected to determine the perceptions of object orientation, whether illusory perceptions of orientation and rotation using a trapezoidal window, or accurate perceptions of orientation and rotation using a rectangular window, are produced.

Other phenomena associated with misperceptions of orientation explained by exclusively considering the perceived directions and perceived distances of the points or parts of the display, together with the observer's information of a constant or changing position of the head, are illustrated in Figure 6. The drawing of Figure 6A represents a situation in which an object physically oriented at $e f$ but perceptually at an illusory orientation $e^{\prime} f^{\prime}$ (for whatever reason) is viewed while the head is physically moved, repetitively, left and right through a perceived distance $K^{\prime}$. The distance information producing the illusory perception of orientation might be misleading perspective cues (e.g., a trapezoidal window), or misleading cues of binocular disparity, or any other source of error in perceived depth combined with substantially accurate perceptions of direction. At Head Position 1, the object appears at $e_{1}^{\prime} f_{1}^{\prime}$ and at Head Position 2, it appears at $e_{2}^{\prime} f_{2}^{\prime}$. Thus, point $f^{\prime}$ appears to move a lateral distance $W_{\mathrm{f}}^{\prime}$ in the same direction as the head motion, and point $e^{\prime}$ appears to move a lateral distance $W_{\mathrm{e}}^{\prime}$ opposite to the direction of the head motion. If the perceived directions to $e$ and $f$ are accurate, as is suggested in this case by the solid direction lines, then the illusory apparent rotation of the extended object, as indicated by the dashed lines and the angle $\beta^{\prime}$, is due to the error in the perception of depth. The same errors of orientation, $e_{1}^{\prime} f_{1}^{\prime}$ or $e_{2}^{\prime} f_{2}^{\prime}$, also can occur when the display is viewed statically - that is, with the head physically stationary at different times at head Position 1 or 2, respectively. However, the change in the perceived orientation of $e f$, occurring in Figure 6A between Position 1 and Position 2, will be the same using static or dynamic conditions of observation only if the perceived error in depth is the same in the two conditions. When the head moves left and right between Positions 1 and 2, the situation contains the cue of relative motion parallax. If this depth cue, which is not present when one is observing statically from Position 1 or 2 , is effective to a significant degree, it will result in a reduction in the apparent rotation $\left(\beta^{\prime}\right)$ of $e f$ for the dynamic as compared with the static condition. Such a result, however, would remain consistent with the phenomenal geometry determined by the factors of perceived direction, perceived distance, and the observer's awareness of being stationary or moving.

The drawing of Figure 6B represents the same errors in the perceived orientation, $e$ ' $f^{\prime}$, of an object, $e f$, extending in depth, as in Figure 6A. In this case, however, the observer always is physically stationary and the extended object physically moves left and right, repetitively, through a perceived lateral distance, $M^{\prime}$, with $M^{\prime}$ equal to the perceived head motion $K^{\prime}$ in Figure 6A. The near point $e$ appears to move through $K^{\prime}+W_{e}^{\prime}$ and the far point $f$ through $K^{\prime}-W_{\mathrm{f}}^{\prime}$ where $W_{\mathrm{e}}^{\prime}$ and $W_{\mathrm{f}}^{\prime}$ are the same in Figures $6 \mathrm{~A}$ and $6 \mathrm{~B}$. If these perceptual conditions occur, it follows that the perceived rotation, $\beta^{\prime}$, will be the same in the situations of Figures 6A and 6B. Again, if the extended object in Figure 6B is seen only when it is at the right or at the left physical position (static stimulus condition) instead of during the right or left motion of the points (dynamic stimulus condition), the perception of orientation $e_{1}^{\prime} f_{1}^{\prime}$ and $e_{2}^{\prime} f_{2}^{\prime}$ will be the same as in the dynamic condition, but only if the cue of relative motion parallax in the dynamic condition is ineffective. Experiments have been conducted to compare the results from such static and dynamic conditions (Gogel \& Tietz, 1990). In this case, illusory orientations $e_{1}^{\prime} f_{1}^{\prime}$ and $e_{2}^{\prime} f_{2}^{\prime}$ of the object, similar in principle to those of Figures $6 \mathrm{~A}$ and $6 \mathrm{~B}$, were produced by binocular disparity using a polarizing stereoscope. It was found, from an analysis of variance involving the situations of both Figure 6A and Figure 6B, that the illusory rotations $\beta^{\prime}$ were not significantly different (at the .05 level) when the terminal (right or left) 


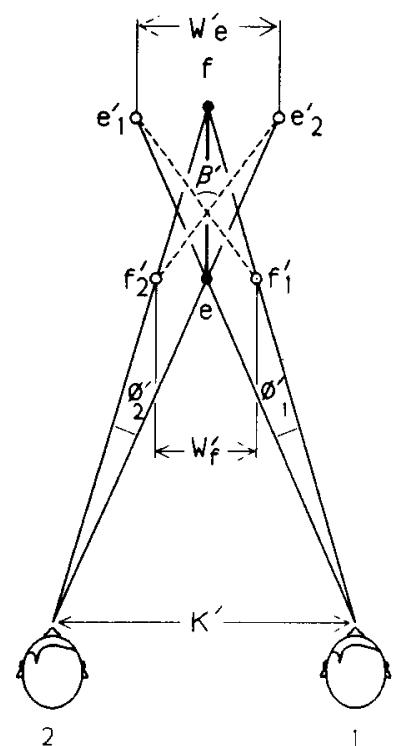

A

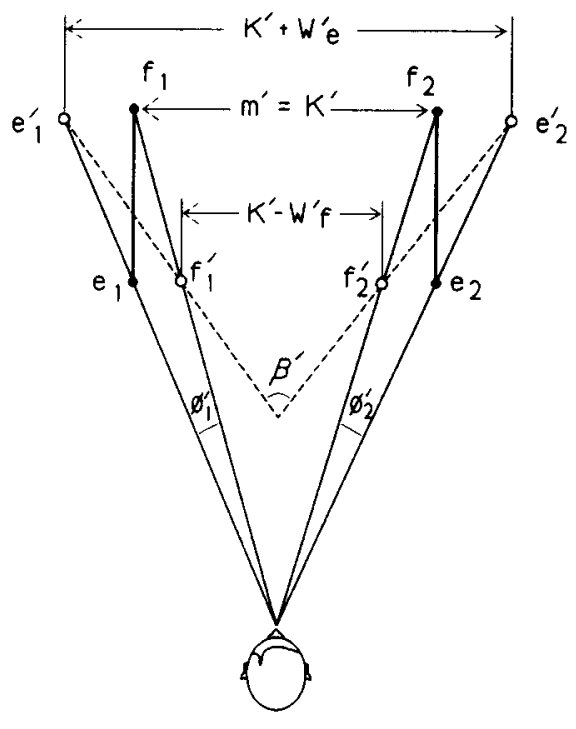

Figure 6. Top view drawings illustrating the perceived angle $\beta^{\prime}$ between changes in the apparent orientation of an object $e f$ as a result of viewing the object at the illusory orientations $e_{1}^{\prime} f_{1}^{\prime}$ and $e_{2}^{\prime} f_{2}^{\prime}$. In Figure $6 \mathrm{~A}$, the object is physically stationary and is viewed while the head is moved through a sensed lateral distance $K^{\prime}$. In Figure 6B, the object is moved laterally through a perceived distance $S^{\prime}$ equal to $K^{\prime}$ in Figure 6A. It is likely, under these conditions, that $\beta^{\prime}$ in the situations represented by Figure $6 \mathrm{~A}$ and Figure $6 \mathrm{~B}$ will be equal.

positions of the display relative to the head were viewed statically as compared with viewing the same terminal positions during continuous head or stimulus motion. Nor from this analysis were the $\beta^{\prime}$ values significantly different (at the .05 level) when the results from the situations of Figures 6A and 6B were compared. It seems that, for both the static and the dynamic conditions, the illusory rotations obtained in the situations of Figure 6 can be understood (assuming that the observer is aware of his or her own motion or lack of it) solely in terms of the sensory cues determining the perceived directions and perceived distances of the parts of the stimulus.

An object that produces illusory motion identical in principle to the phenomena illustrated in Figures 5 and 6 is a transparent face mask reversible in depth (see Gregory, 1970). The illusory motion of the face mask is shown in Figure 7 for the case of a physically stationary mask viewed monocularly by an observer laterally moving the head between Positions 1 and 2. As is shown in Figure $7 \mathrm{~A}$, the mask is physically oriented with the nose pointing away from the observer, but the mask appears inverted; for example, the nose appears to be pointing toward the observer. Thus, the perceived depth $\left(e^{\prime} f^{\prime}\right)$ of the parts of the mask is opposite in direction to the physical depth $(e f)$ of these same parts. Figure 7B diagrams the apparent rotation $\beta^{\prime}$ of this physically stationary mask as the head of the observer moves laterally. The similarities between Figures $6 \mathrm{~A}$ and 7 are obvious. An illusory horizontal rotation of the mask also will be seen if the observer is stationary and the mask is physically moved laterally, or an illusory vertical rotation is seen if the mask is slanted physically in depth toward or away from a stationary observer. The latter perceptions also are very likely to be understood in terms of perceived distance, perceived direction, and the observer's perception of selfmotion or stationariness.

Additional demonstrations of illusory motions of extended stimuli that reflect the contribution of the basic factors involved in phenomenal geometry are available. Illusory motions similar in principle to those illustrated in Figures 5-7 can be seen when perceived depth is in error, using a Necker cube, or a Mach folded card, or a stereogram. A colleague, Jack Loomis, has called my attention to a demonstration likely to be of the same kind. A strip of white paper fashioned into a short tube and placed upright on a surface will sometimes be seen as inverted in depth if it is viewed monocularly. When this occurs, the tube will appear to be tilted at a shallow angle with respect to the surface, rather than appear upright. Movement of the head will cause the tube to appear to wobble. Interesting effects also are obtained if the tube at its illusory orientation is rolled on the surface while viewed with a stationary head. If a stereokinetic display such as Duncan's "Leaning Tower" (Duncan, 1975) is monocularly viewed during its rotation, it will appear vividly to be extended in depth, with the motion of the 


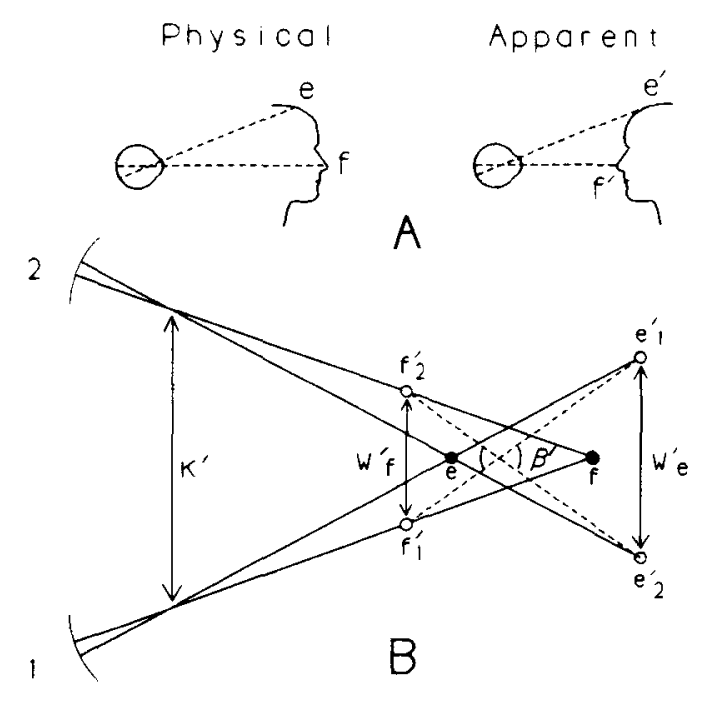

Figure 7. The effect of a perceptual reversal of the depth of a face mask (Figure 7A) on the illusory rotation $\beta^{\prime}$ of the mask concomitant with a lateral motion of the head (Figure 7B). Similar effects are obtained if the head is stationary and the mask is moved (similar to Figure 6B) or the mask is stationary while viewed with a moving head (similar to Figure 6A). The perceptions can be explained by the correct perception of the directions to the parts of the mask, the correct perception of the observer's own motion, and the illusory perception of depth within the mask.

tower tracing an inverted cone around the observer's line of sight to the base of the tower. If, instead of viewing the display from a position directly above the base of the tower, the head is located to the right or left, the axis of the cone of perceived rotation will change so as to remain symmetrical to the observer's line of sight, illustrating the effect of varying perceived direction for a constant error in perceived distance. Whatever the cause of the error in perceived depth in the stereokinetic phenomenon, that error plus perceived direction and the apparent position of the observer will predictably determine what is perceived, consistent with phenomenal geometry.

Still further displays for which the theory of phenomenal geometry has implications are the changes in the perceived orientation of pictured objects designed to look threedimensional (Cutting, 1988; Ellis, Smith, \& McGreevy, 1987; Goldstein, 1979, 1987, 1988) as a consequence of changes in the viewing position of the observer. Such phenomena are obviously related or identical to the orientation in perceived depth associated with realistic pictures of a face, or to the orientation in perceived depth between parts of a stereogram, or to the description of the orientation of the cone of perceived movement of a stereokinetic display. As discussed in relation to Figures 5, 6, and 7, the perceptions associated with distance, direction, and observer position or motion are sufficient to specify the perceived orientation of either real or simulated stimuli as found either in two-dimensional drawings or pictures, or in three-dimensional displays. For example, in Fig- ure 7 , the perceived direction in which the portrayal of a face appears to be pointing relative to the observer involves the same processes, whether it is a realistic twodimensional portrait or actually a three-dimensional replica in an illusory or a nonillusory orientation. The magnitude or changes in direction of the perceived orientation in depth of the stimulus in these several cases will differ as the head or the stimulus is moved, but the processes underlying these phenomena are expected to be the same, consistent with phenomenal geometry.

It is asserted that all of the above phenomena involving single or multiple test objects or objects extended in depth can be understood in terms of the theory of phenomenal geometry. Also, consistent with the theory, if in addition to the illusory rotations, the entire stimulus configuration appears closer to or farther from the observer than its physical distance, the entire configuration will appear to move laterally with or against the motion of the head.

\section{SUMMARY OF THE EVIDENCE FOR THE THREE BASIC FACTORS IN PHENOMENAL GEOMETRY}

The contribution of perceived distance or depth to the perceptual localization of stimuli in phenomenal geometry is well established. Using the head motion procedure, it has been found that distance or depth cues that would be expected to modify perceived distance will also, as predicted from phenomenal geometry, modify the illusory translation $\left(W^{\prime}\right)$ or illusory rotation $\left(\beta^{\prime}\right)$ concomitant with a motion of the head. In practice, the procedure has been simplified by assuming that the conditions are such that Equation 2 can be used. According to Equation 2, for known values of $K$ and $D_{\mathrm{p}}, D^{\prime}$ can be calculated from the observer's indication of $W^{\prime}$. Or, $D_{\mathrm{p}}$ can be adjusted by moving the test object physically $(W)$ in a direction (phase) opposite to its apparent motion $\left(W^{\prime}\right)$ until $W^{\prime}$ is nulled $\left(W^{\prime}=0\right)$. When this is achieved, it follows from Equation 2 that $D_{\mathrm{p}}=D^{\prime}$; that is, $D_{\mathrm{p}}$ at the null adjustment is a measure of the perceived distance $\left(D^{\prime}\right)$. Results obtained using the head motion procedure have been applied to the measurement of perceived depth or distance from oculomotor cues of convergence and accommodation (Gogel, 1977, 1982), perspective (Gogel \& Tietz, 1974), relative size (Gogel, 1976), binocular disparity (Gogel, 1980) the specific distance tendency (Gogel \& Tietz, 1973), the equidistance tendency (Gogel, 1979a; Gogel \& Tietz, 1977), familiar size (Gogel, 1976), and absolute motion parallax (Gogel \& Tietz, 1979). The importance of perceived direction for the geometry also is supported by the effect on $W^{\prime}$ in Equation 2 of changing the pivot distance independently of the apparent distance, as in the case of the null adjustment (Gogel, 1976, 1977, 1979a, 1982; Gogel \& Tietz, 1974, 1979; MacCracken, Gogel, \& Blum, 1980). The extent of the lateral motion of the head also has been found to be a significant factor in determining $W^{\prime}$, as was demonstrated by the change 
in the magnitude of the illusory motion, as a consequence of a change in the magnitude of the head motion, for a constant perceived distance (Gogel \& Tietz, 1977).

\section{OTHER EXPLANATIONS OF THE PERCEIVED ROTATION OF MULTIPLE OBJECTS OR OBJECTS EXTENDED IN DEPTH}

The VOR theory cannot explain the illusory rotation of stimuli extended in depth concomitant with head motion. An illusory rotation signifies that different parts of the object appear to move simultaneously in opposite directions, whereas only a perception of motion in one direction can occur at any one time from pursuit eye movements.

Another explanation of illusory rotation concomitant with head motion is that it is a direct response to relative motions on the retina (for discussions of this problem, see Gogel, 1981a, 1983; Peterson \& Shyi, 1988; Shebilske \& Proffitt, 1981, 1983). Whenever stimuli are distributed in depth, their images on the eye will undergo different motions as the head is moved laterally. But these retinal motions are not sufficient to determine the perceived illusory rotation, as is shown by keeping the same physical stimulus distribution in depth while varying the perceived depth. In this case, the perceived rotation, according to phenomenal geometry, will change systematically and predictably as the perceived depth is changed (Gogel, 1980). Two situations illustrating this prediction are shown in Figure 8. In this figure, a physically stationary rod at a constant physical slant in depth is perceived at a different illusory slant in Figures $8 \mathrm{~A}$ and $8 \mathrm{~B}$. As a consequence of the different errors in perceived depth in the two situations, the apparent rotation shown by the angle $\beta^{\prime}$ is predictably different in the two cases. This is expected to occur, according to phenomenal geometry, even though the retinal motion of the top $(t)$ relative to the bottom $(b)$ of the rod, as determined by the physical slant of the rod, is identical in the two instances. In Figure 8A, the direction of the apparent rotation of the rod (although not the amount) is consistent with that expected exclusively from the retinal motion. In Figure 8B, neither the direction of apparent rotation of the rod nor its apparent amount is predictable exclusively from the retinal motion. That results consistent with these predictions from phenomenal geometry are obtained has been shown in the study by Gogel (1980) of this phenomenon. The predictability from phenomenal geometry of these apparent rotations obtained with a moving head provides clear limitations of the ability to understand the geometry of perceived space from retinal (or reafference) information without considering the role of perceived depth or distance.

Stereograms, because they produce an illusory depth between parts of the display, provide another example of

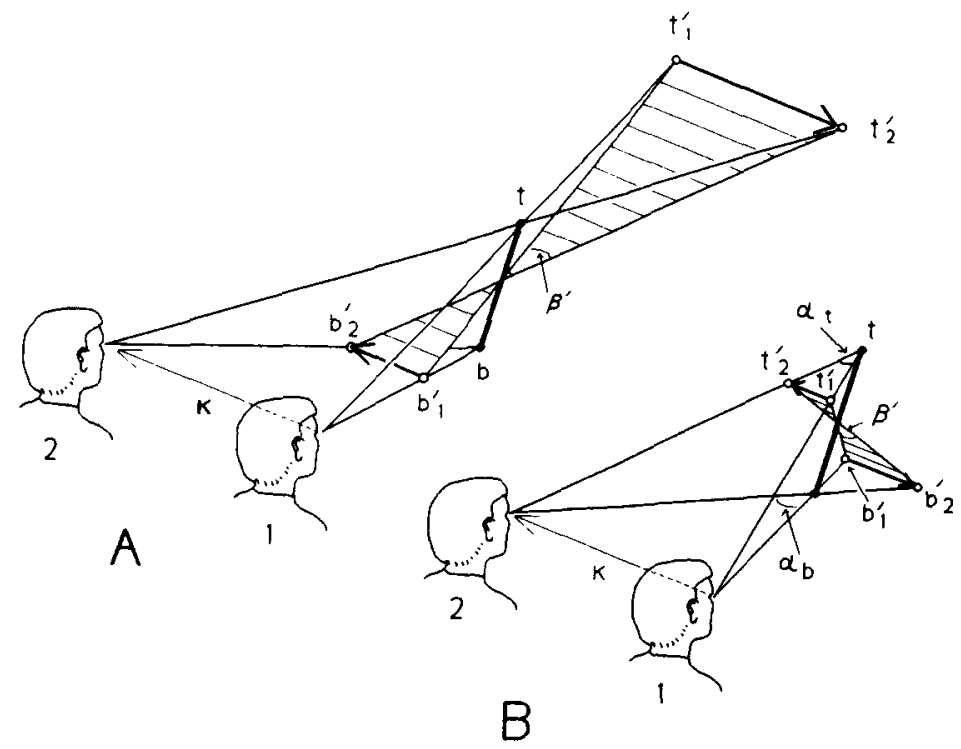

Figure 8. Apparent illusory rotation concomitant with a lateral motion of the head of a line $(t b)$ slanted in depth, with $t$ physically more distant than $b$. In Figure $8 \mathrm{~A}$, the perceived slant is in the same direction as the physical slant but is greater in magnitude, and the apparent rotation $\left(\beta^{\prime}\right)$ of the line is consistent in direction (but not in magnitude) with that expected solely from the relative motion on the retina. In Figure 8B, the perceived slant of the line is in a direction opposite to the direction of the physical slant, and the apparent rotation $\beta^{\prime}$ of the line is opposite to that expected solely from the direction of the relative motion on the retina. (From "The Sensing of Retinal Motion" by W. C. Gogel, 1980, Perception \& Psychophysics, 28, p. 157. Copyright 1980 by The Psychonomic Society, Inc. Reprinted by permission.) 
the apparent rotation illustrated in Figures $6 \mathrm{~A}, 7$, and 8 and obtained as the head is moved laterally. Rock (1983) has classified this and the similar apparent rotation obtained with an apparent depth inversion of a Necker cube as cases of perceptual intelligence. It is as though the perceived depth generates certain expectations of stimulus changes on the retina as the head is moved. Since these changes do not occur or are inconsistent with the expectations, a reasonable conclusion is that the scene must have rotated in the direction required in order to produce the stimulus changes obtained. As stated by Rock (1983): "It would seem that the perceptual system 'knows' certain laws of optics that normally obtain and then 'interprets' seeming departures from these laws in such a way as to be compatible with them. In doing so, it invents or constructs environmental events that logically would have to be occurring to account for the unexpected stimulus change or lack of change" (pp. 10-11). According to the phenomenal geometry explanation favored in the present article, the only requirement for explaining these phenomena is that the object or parts be localized in perceptual space by whatever information is effectively available to determine perceived direction, perceived distance, and the observer's perception of self-motion or stationariness. The same localization processes-and, therefore, the same explanation-apply whether either the observer or the stimulus is moving or stationary and whether the perception of direction and/or depth is veridical or grossly in error. Knowledge of the laws of optics by the perceptual system is not needed.

Wallach $(1985,1987)$ explains the perception of illusory rotation of a stationary object as viewed by a laterally moving observer in terms of compensation processes. Consider the situation in which a stationary object that is physically three-dimensional is viewed as the observer's head moves laterally. The changes in the position of the head resulting from the lateral motion will produce changes in the image of the stationary object on the retina. But, because the observer has knowledge of his own motion, these changes will not result in the perception that the object has rotated. The information about the motion of the head compensates for the changing proximal stimulus, so that the object is perceived to remain stationary. Suppose, however, that instead of an actual three-dimensional object, a realistic two-dimensional drawing of the three-dimensional object is presented such that the object is perceived to be three-dimensional. In this case, as the observer's head moves laterally, the retinal image of the drawing undergoes little, if any, change. But the compensation will still be applied, resulting in the perception that the object has rotated.

A limitation of compensation theory in explaining illusory or lack of illusory rotation as the head is moved laterally is that it does not take into account the role of errors in perceived depth in these phenomena. For example, in the case just cited, a more exaggerated illusory rotation of the object for the same perceived depth would have been obtained, according to the theory of phenomenal ge- ometry, if a physically three-dimensional but perceptually depth-inverted object had been used instead of the two-dimensional drawing. It is difficult to see how these phenomena can be explained without considering the magnitude and direction of errors in perceived depth. This limitation in the theory remains if the process of compensation expressed by the reafference principle (von Holst \& Mittelstaedt, 1950) that normally is applied to eye movements is extended to situations involving a motion of the head. The reafference principle is designed to permit the observer to distinguish between proximal changes produced by the observer's own motion and changes produced by motions of the physical stimulus. When a lateral motion of the head is involved, it is obvious from the previous discussion that the ability to perceive a stationary object as stationary despite retinal motion will depend on the perceived distance of and perceived depth within the stimulus object, in addition to information about perceived directions and the observer's own motion. Indeed, it is unlikely, in the absence of a background environment, that the observer can discriminate between illusory and real motion or rotation of a test stimulus. Evidence that real and illusory motion can be perceptually equivalent is found in (1) studies that show that illusory motion concomitant with head motion can be nulled out by real motion (Gogel, 1977, 1979a, 1981a, 1982; Gogel \& Tietz, 1979; MacCracken et al., 1980), (2) studies in which the illusory and real motion add vectorially (Gogel, 1979a; Gogel \& Tietz, 1979), and (3) a study indicating the inability to distinguish perceptually between a real and an illusory rotation of a Necker cube (Peterson \& Shyi, 1988). Particularly difficult for either a compensation theory or a theory according to which perception is similar to problem solving is the similarity of perceived differences in stimulus orientation that can occur with static and dynamic stimulus/observer conditions, as has been discussed with respect to Figure 6. In the case of the static stimulus/observer conditions, compensation from observer motion is not available, nor is there a problem to solve.

\section{HYPOTHESES IN APPLYING THE THEORY OF PHENOMENAL GEOMETRY}

\section{The Hypothesis of Cue Equivalence}

In the interest of predictive parsimony, it is assumed, in applying the theory of phenomenal geometry, that the factors of perceived direction, perceived distance, or the observer's sensing of self-position will have the same consequences for the perceived localization of stimulus points and, hence, for the derived perceptions of size, shape, orientation, and motion, regardless of which sources of information determine these perceptions. For example, the perceived width $\left(S^{\prime}\right)$ of a stimulus extending between two perceived directions $\left(\theta^{\prime}\right)$ will have the same relation to perceived distance $\left(D^{\prime}\right)$, regardless of whether the perceived distance is determined by one or another of the binocular or monocular cues of distance or by any other 
factor capable of modifying perceived distance, such as the effect of adjacent context (Gogel \& Mershon, 1977), or the allocation of attention (Gogel et al., 1985). Similarly, the effect of perceived direction on the derived perceptions will be the same, whether the perceived direction is modified by pursuit eye motions or by the Roelofs' effect (1935) or by any other factor, as long as the modification is indeed perceptual. This hypothesis, called the hypothesis of cue equivalence or cue substitution, has the effect of making the phenomenal geometry very parsimonious. Perception is the final channel through which a variety of effects or cues are funneled to produce a particular perceptual outcome. But this same perceptual outcome can be produced by the appropriate values of any other effective set or mixture of cues or other sources of perceptual information.

There are at least three kinds of evidence for the hypothesis of cue equivalence-evidence, that is, that different sources of information or cues can contribute to or determine the same perception. One kind results from a procedure for measuring the perceived distance of or depth between parts of the visual field. This method consists of adjusting a probe object (often a luminous point) to appear at the same distance as the parts of the visual scene of interest (Deregowski, 1980; Gogel, 1954, 1970; Gogel \& Harker, 1955; Gregory, 1968). The probe object may utilize cues of distance different from those found in the portion of the visual field to which the probes' perceived distance is adjusted. Or a comparison field, again involving a configuration of distance or depth cues different from those found in the test object, may be used to measure the perceived distance of the test object (Ittelson, 1952, chap. 7). A second kind of evidence is the ability of two motions involving different sources of perceived motion (e.g., real and illusory) to add vectorially (Gogel, 1979a, 1979b; Gogel \& Tietz, 1977; Wallach, Bacon, \& Schulman, 1978; Wallach \& Frey, 1969). Under these conditions, the visual system presumably accepts both sources as contributing to the same perception. A third kind of evidence is found in situations in which the perception represents a compromise between conflicting cues (Gillam, 1968; Gogel, 1970; Ittelson, 1968; Schriver, 1925; van der Meer, 1979). In these situations, the different sources contribute to the same final perception, which quantitatively is often unlike the perception expected from either source alone. A somewhat more elaborate discussion of the evidence for the assumption of cue equivalence is found in Gogel (1984, pp. 32-36).

\section{The Hypothesis of Internal Consistency}

A second hypothesis involved in the theory of phenomenal geometry is that the geometry is internally consistent. Internal consistency requires that the perceptions of size, shape, orientation, and motion that are derived from perceived spatial locations defined by perceptions of direction, distance, and self-position must be consistent with those perceived spatial locations. Examples of responses $(R)$ obtained from a stationary observer that would indicate internal consistency or inconsistency, if they were interpreted as measuring perceptions, are contrasted in Figure 9. In Figure 9, an observer presented with a rectangular stimulus at some distance is instructed

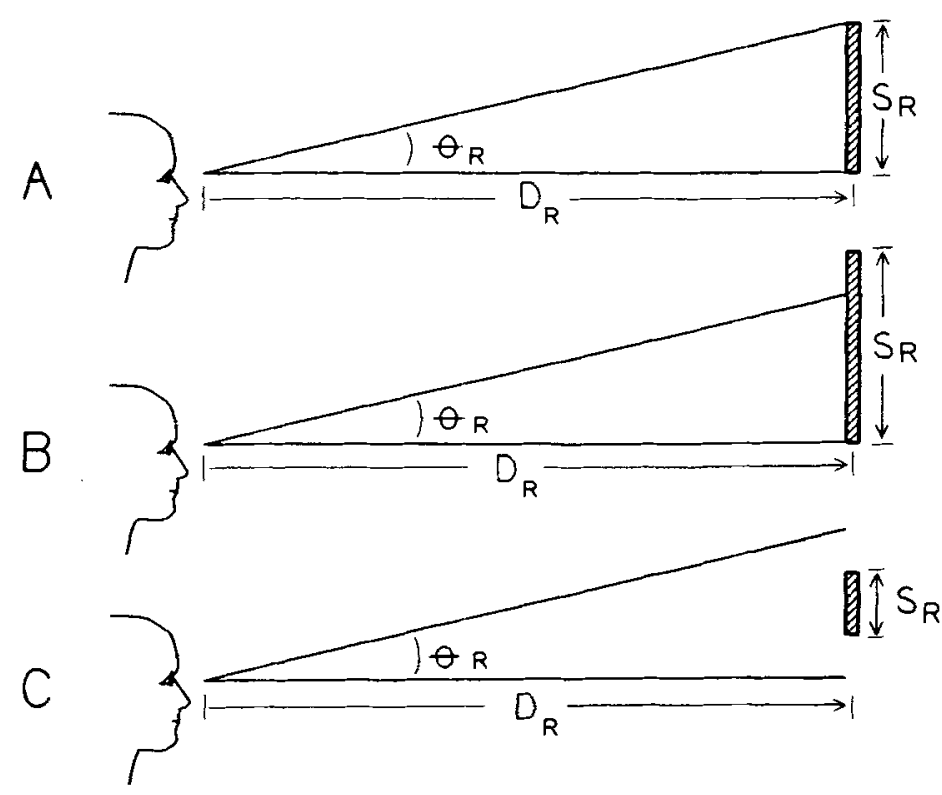

Figure 9. Drawings contrasting internal consistency (Figure 9A) and a lack of internal consistency (Figures $9 \mathrm{~B}$ and $9 \mathrm{C}$ ) in the observer's reports $(R)$ of the visual angle $\theta_{R}$, the distance $D_{R}$, and the size $S_{R}$ of the stimulus object. Unlike the situation of Figure $9 A$, in Figures $9 B$ and $9 C$, the reported size of the stimulus is too large or too small, respectively, to be consistent with the reported visual angle of the stimulus at its reported distance. 
to indicate its perceived distance $D^{\prime}$, perceived size $S^{\prime}$, and the change in perceived direction $\theta^{\prime}$ between its top and bottom. The observer's responses $(R)$ are labeled $S_{\mathrm{R}}$, $D_{\mathrm{R}}$, and $\theta_{\mathrm{R}}$. Assuming that these responses are measures of what is actually perceived, in Figure $9 \mathrm{~A}$, since $S_{\mathrm{R}} / D_{\mathrm{R}}$ $=\tan \theta_{\mathrm{R}}$, it follows that $S^{\prime} / D^{\prime}=\tan \theta^{\prime}$, in agreement with a strict form of the SDIH. It can be concluded in this case that the phenomenal geometry is internally consistent. In Figures $9 \mathrm{~B}$ and $9 \mathrm{C}$, however, $S_{\mathrm{R}} / D_{\mathrm{R}} \neq \tan \theta_{\mathrm{R}}$; that is, $S_{R}$ does not fit the extent specified by the combined information given by $D_{\mathrm{R}}$ and $\theta_{\mathrm{R}}$. If it can be assumed that the responses shown in Figures $9 \mathrm{~B}$ and $9 \mathrm{C}$ also measure perceived characteristics, it can be concluded, in disagreement with the strict form of the SDIH, that $S^{\prime} / D^{\prime} \neq \tan \theta^{\prime}$. In these cases, the hypothesis of internal consistency in the phenomenal geometry is violated. It is seldom that responses measuring all three perceptions $\left(S^{\prime}, D^{\prime}\right.$, and $\left.\theta^{\prime}\right)$ are obtained in experiments. However, it is not unusual to find instances often similar to those indicated by Figures $9 B$ and $9 C$, in which the strict form of the SDIH exemplified by Figure 9A and Equation 6 and needed for phenomenal internal consistency is not satisfied (see Epstein \& Landauer, 1969; Foley, 1968, 1972; Gogel, 1977; Gogel et al., 1985; Gogel \& Sturm, 1971). ${ }^{2}$

A still more extreme case in which the strict form of the SDIH is not always consistent with the obtained responses is called the size-distance paradox. This paradox is clearly inconsistent with the requirement of internal consistency in the phenomenal geometry if, indeed, the measurements obtained in this paradox are purely perceptual. In the size-distance paradox, objects of the same shape (same possible identification) and subtending the same visual angle are presented at different distances from the observer, often with oculomotor cues being the only source of distance information. It is found that although the change in the perceived size of the test object is consistent with its change in physical size, as is expected from the SDIH, the change in its perceived distance is not consistent with the SDIH (Biersdorf, 1966; Heinemann, Tulving, \& Nachmias, 1959; Komoda \& Ono, 1974; Ono, Muter, \& Mitson, 1974). Another example of this paradox is the moon illusion, in which the horizon moon appears larger than the zenith moon but often is reported as being closer not farther than the zenith moon (as would be required by the SDIH and by internal consistency). A study by Swanston and Gogel (1986) provides another instance of results grossly inconsistent with the SDIH. A luminous line viewed monocularly in an otherwise dark environment was made to increase or decrease in length so as to represent approach or recession from the observer. Although the expected changes in perceived depth were obtained, it also was found that the perceived length of the line changed by amounts approximating its change in angular length. This result is inconsistent with the SDIH. To the degree that the line appeared to approach or recede, to that degree its perceived size should have appeared to remain more constant than would be expected from its changing visual angle.

\section{EXPLANATIONS FOR SEEMING FAILURES OF INTERNAL CONSISTENCY IN PHENOMENAL GEOMETRY}

There are several possible explanations for these seeming failures of internal consistency in the phenomenal geometry, as they are illustrated by failures of the SDIH. Using binocularly viewed points of light in an otherwise dark room, Foley (1972) found that observers adjusted a frontal extent to be about one half as large as its distance from the observer in order for the two extents to appear equal. This implies that the constant of proportionality in the SDIH relating $S^{\prime} / D^{\prime}$ and $\tan \theta$ is considerably greater than unity. This result, together with that from a previous study (Foley, 1965) in which it was found that perceived visual angle usually exceeded physical visual angle by about only $10 \%$, suggested that the intrinsic geometry of visual space was non-Euclidean. It was found, however, that subjective space became more Euclidean as distance information was increased (Foley, 1972). Also, it should be noted that the values of the constant of proportionality in the SDIH obtained in various experiments can vary considerably for different observers and different procedures, with this value possibly becoming less than one for quite small values of $\theta$ (Gogel, 1977; Gogel \& Sturm, 1971; Landauer \& Epstein, 1969). But, whether the phenomenal geometry is described as Euclidean or as non-Euclidean does not remove the need to consider the geometry in terms of the three basic factors of perceived direction, perceived distance, and the perceived motion or stationariness of the observer.

McCready $(1965,1985,1986)$ has advocated that the perceived visual angle $\left(\theta^{\prime}\right)$ be used instead of the physical visual angle $(\theta)$ in the SDIH. Furthermore, McCready $(1985,1986)$ has proposed that the size-distance paradox, including the paradox of the moon illusion, can be explained in terms of variations in $\theta^{\prime}$. This explanation would be plausible if sufficiently large changes in $\theta^{\prime}$ (despite the constant $\theta$ ) occurred in the object misjudged in distance in the size-distance paradox. Similarly, if the $\theta^{\prime}$ of the moon on the horizon in the moon illusion were sufficiently larger than the $\theta^{\prime}$ of the zenith moon, the paradox produced by the report that the horizon moon is seen as both larger and nearer than the zenith moon would be resolved, and in both cases the seeming inconsistency with respect to the SDIH and phenomenal geometry would disappear. Unfortunately, there is no evidence that the needed changes in $\theta^{\prime}$ do occur.

A third explanation of the internal geometrical inconsistencies indicated by failures of the SDIH is the modification of the results by cognitive (nonperceptual) factors. One such factor that has been identified is called off-sized judgments (or off-sized perceptions). ${ }^{3}$ This is the notion that an object seen to be larger or smaller than its assumed or standard (normal) size is judged to be at a nearer or farther distance, respectively, than the distance at which it is perceived. Let $S_{\mathrm{s}}$ be the remembered size of the standard $(s)$. Let $S_{\mathrm{t}}^{\prime}$ be the perceived size $S^{\prime}$ of the test object 
$(t)$ being viewed. Off-sized judgments occur whenever the ratio of the assumed size $\left(S_{\mathrm{s}}\right)$ provided by experience with a standard size and the perceived size $\left(S_{t}^{\prime}\right)$ of the test object differ-that is, whenever $S_{\mathrm{s}} / S_{\mathrm{t}}^{\prime} \neq 1$, where $S_{\mathrm{s}} / S_{\mathrm{t}}^{\prime}$ is the inverse of the off-sized judgment. For example, if a playing card with a standard size of $5.7 \times 8.9 \mathrm{~cm}$ is seen to be $2.35 \times 4.45 \mathrm{~cm}$ in size, it is seen as a half-sized playing card $\left(S_{\mathrm{s}} / S_{\mathrm{t}}^{\prime}=2\right)$. Since the standard or normalsized playing card is customarily seen at various distances from the observer, it provides only a standard size, not a standard distance. Some standard objects provide both. For example, for a test object presented in the sizedistance paradox, the standard size $\left(S_{\mathrm{s}}\right)$ is the memory of the perceived size of the object of the same shape presented first, and the standard distance $\left(D_{s}\right)$ is the memory of the perceived distance of this first presentation. The standard size $S_{\mathrm{s}}$ and the standard distance $D_{\mathrm{s}}$, when applied in determining the observer's response to the test object, are considered to be cognitive. They both involve the storage and retrieval of an internal (mental) representation associated with the standard object.

The equation for calculating the observer's frequent response to distance $\left(D_{\mathrm{R}}\right)$, when the observer is presented with a test object that is judged to be off-sized and for which a standard distance is not available, is

$$
D_{\mathrm{R}}=D_{\mathrm{t}}^{\prime}\left(S_{\mathrm{s}} / S_{\mathrm{t}}^{\prime}\right)
$$

In Equation 8, $D_{\mathrm{t}}^{\prime}$ is the perceived distance of the test object and $D_{\mathrm{R}}$ is the observer's response of the distance of the test object reflecting the effect of the off-sized judgment. In a situation such as the size-distance paradox or the moon illusion, in which a standard distance $\left(D_{\mathrm{s}}\right)$ as well as a standard size $\left(S_{\mathrm{s}}\right)$ is available from memory, the remembered value of $D_{\mathrm{s}}$ is likely to be used by the observer in place of $D_{\mathrm{t}}^{\prime}$, and Equation 8 then becomes

$$
D_{\mathrm{R}}=D_{\mathrm{s}}\left(S_{\mathrm{s}} / S_{\mathrm{t}}^{\prime}\right) \text {. }
$$

The consequences of Equation 8 for the SDIH and thus by implication for the hypothesis of internal consistency of phenomenal geometry are discussed in several articles (Gogel \& DaSilva, 1987a, 1987b; Gogel \& Sturm, 1971; Swanston \& Gogel, 1986) and will only be summarized here. As a hypothetical example of the effect of an offsized judgment on the response to distance $D_{\mathrm{R}}$ that is consistent in principle with the results from several studies (Gogel, 1969a; Gogel \& DaSilva, 1987a; Gogel \& Newton, 1969), consider the case of a familiar object (e.g., a guitar of normal size) located $9 \mathrm{~m}$ from an observer and viewed monocularly in a dark environment. In this case, it is likely that the guitar will appear to the observer to be at a closer distance, perhaps at about $3 \mathrm{~m}$. This error is considered to be a consequence of the "specific distance tendency," which, in the absence of effective egocentric cues of distance, results in an object's appearing at a relatively near distance from the observer, regardless of its physical distance (Gogel, 1969b; Gogel \& Tietz, 1973). Because the guitar appears at about one third of its physical distance, in agreement with the SDIH, it will be seen to be about one third the size of a normal guitar, such that $S_{s} / S_{\mathrm{t}}^{\prime}$ is about 3 . The observer's report of distance $D_{\mathrm{R}}$, however, often will deviate from the perceived distance toward the physical distance of the guitar as a result of the off-sized judgment. If the off-sized judgment were to completely determine the verbal report (usually the effect is only partial), the report of distance would be accurate; that is, $D_{\mathrm{R}}=3 \mathrm{~m} \cdot 3=9 \mathrm{~m}$, according to Equation 8. As is indicated by this example, the usefulness of this cognitive process resulting from off-sized judgments is that the verbal report of distance can be more accurate than it would have been had it been based exclusively on the erroneously perceived distance. But, it seems that the observer, when asked to judge the perceived size of the familiar object, often responds with the size as it is perceived rather than with the familiar size. The combination of perceived size and cognitively modified $D_{\mathrm{R}}$ produces seeming variations in the constant of proportionality relating $S^{\prime} / D^{\prime}$ and $\tan \theta$ in the SDIH. Results of this kind are consistent with data obtained by Gogel (1969a) and Gogel and DaSilva (1987a).

As is suggested by the discussion of the size-distance paradox, off-sized judgments are not limited to familiar objects. They can occur in any situation in which a standard size is remembered as different from the size of the test object. Coltheart (1968) and Gogel and Sturm (1971) have proposed that test objects such as a disk or rectangle that have a range of physical sizes nevertheless often tend to have an assumed or standard size. The ranges of such "nonfamiliar" objects generally are greater than those of more "familiar" objects, such as a guitar, so that the judgment that the disk or rectangle is off-sized is likely to be less precise than in the case of the guitar. Nevertheless, off-sized judgments with plain geometrical objects seem to occur. This is supported by the study of Gogel and Sturm (1971) in which it was found, even on the first presentation of a rectangle viewed under reduced conditions, that substantial deviations from unity occurred for the proportionality constant relating $S^{\prime} / D^{\prime}$ and $\tan \theta$. These deviations were explained by the effect of off-sized judgments. Consistent with this interpretation, it is sometimes found that the reported distance of the first presentation of a large geometrical stimulus is less than that of a small geometrical stimulus, even though a successive comparison between the stimuli is avoided (Coltheart, 1968, Experiment 5; Gogel \& Sturm, 1971). If it is possible for off-sized judgments to occur with any frontal extent, the results obtained by Foley (1972) might be explained by Equation 8 and by the notion that the frontal extent, because of its large off-sized appearance, was judged to be closer than it would if it were not judged as off-sized and that this occurred without a proportionate change in its perceived visual angle. If this were found to be the case, an explanation in terms of non-Euclidean geometry would be unnecessary.

Off-sized judgments also have been applied as an explanation of the failure of the SDIH to predict the $D_{\mathrm{R}}$ results obtained in the optical expansion of a luminous 
line presented in an otherwise dark environment (Swanston \& Gogel, 1986). It was assumed that the perceived size of the initial presentation in the expansion series provided the standard size $S_{\mathrm{s}}$ for judging the subsequent stimuli in the expansion as continuously larger off-sized objects. Equation 9, which involves the memory of both a standard size, $S_{s}$, and a standard distance, $D_{s}$, is designed to predict the reports of distance $D_{\mathrm{R}}$ obtained from the size-distance paradox. In this case, the $S_{s}$, to be used in the off-sized judgment of the test object, is the memory of the perceived size of the identically shaped standard object presented previously; $D_{\mathrm{s}}$ is the memory of the perceived distance of this standard object; and $S_{t}^{\prime}$ is the perceived size of the test object presented second. For the moon illusion, in which the horizon moon is reported to be larger and closer than the zenith moon, in Equation 9, $S_{\mathrm{s}}$ and $D_{\mathrm{s}}$ are the remembered size and distance of the zenith moon, and $S_{\mathrm{t}}^{\prime}$ is the perceived size of the moon on the horizon.

According to this account, the internal consistency of phenomenal geometry can be disturbed by the intrusion of memories of the perceived size and sometimes the perceived distance of standard objects observed, often repeatedly, in the immediate or more remote past. But, if this seeming inconsistency is only found in the responses and not in the perceptions, which the responses are intended to measure, the phenomenal geometry itself cannot be said to be disturbed. Clearly, off-sized judgments contain a cognitive component that makes their possible contribution to the response of size inappropriate for an examination of the SDIH, which is concerned only with perceived characteristics. It is of interest, however, whether offsized perceptions under any conditions can modify the perception of distance or, as in the example of the guitar, can modify only the judgment of or response to distance, with the actual perception of distance unchanged. This question is considered in three studies discussed in Gogel and DaSilva (1987b). To examine this question, measures of perceived distance, using the head motion procedure of Figure 1A and Equation 2, were compared with more direct measures of perceived distance, such as verbal reports. Unlike direct measures, the head motion procedure is assumed to be essentially immune to cognitive intrusions based on off-sized judgments. It was found (Gogel, 1981b) that information leading to off-sized judgments of the test object, provided by presenting large or small examples of familiar objects of the same shape as the test object, had no effect on perceived distance as measured by the head motion procedure. But, such information had a large effect on verbal reports of the distance of the test object. If, however, the information determining the familiar size was contained in the test stimulus (i.e., the test object was a familiar object), it had a small effect on perceived distance as measured by the head motion procedure, but it had a large effect on the verbal report of distance (Gogel, 1976). In the case of optical expansion (Swanston \& Gogel, 1986, Experiment 3), it seems that the off-sized judgments hypothesized to occur had a clear effect on both indirect measures of perceived sagittal motion obtained with the head motion procedure and direct sagittal measures obtained from adjustments of the separation of comparison rods. If it can be assumed that the perceived and physical visual angle were approximately equal in Experiment 3 of the Swanston and Gogel study, the results suggest that at least under rather special conditions a cognitive process can disturb the internal consistency of phenomenal geometry. Effects superposed on the primary (phenomenal) process by cognitive factors, such as off-sized judgments, whether or not they modify perceived distance, are called the secondary process. The secondary process normally tends to reduce systematic errors found in the primary process and caused by limitations in sensory information. Such limitations $\alpha$ cur in reduced conditions of observation, or at far distances, or for isolated stimuli. As suggested by Equations 8 and 9 , the primary process provides a basis for the secondary process. The contribution of the secondary process necessarily decreases, however, as the primary process becomes the main determiner of the response.

Day and Parks (1989) have recently discussed the problems presented by a number of paradoxes. It seems difficult to achieve general laws of visual perception in view of the seeming inconsistencies demonstrated by the paradoxes. For example, the SDIH clearly is necessary for the explanation of many phenomena. But, also, it fails to explain other (e.g., paradoxical) data to which it might be expected to apply. Hopefully, the distinction between primary processes, as defined by phenomenal geometry, and secondary processes, involving cognitive effects, can contribute to the resolution of some of these difficulties. The combination of the two different processes, since they sometimes follow different rules, can result in data that seem paradoxical. The study of the modification or distortion of responses by cognition is in its early stages. It is possible that, through investigation of a number of these paradoxes, the distinction between perceptual and cognitive processes can be sharpened, so that the consequences of cognitive effects are not confused with the purely perceptual processes associated with phenomenal geometry.

\section{IMPLICATIONS OF PHENOMENAL GEOMETRY}

\section{The Role of Perceived Distance}

According to phenomenal geometry, the localization of a stimulus in phenomenal space requires a combination of perceived distance, perceived direction, and the perception of the position or motion of the self. Only when perceptual values of each of these factors are available are perceptions of size, motion, orientation, or shape possible. A size or motion on the retina essentially is specified by the distribution of visual directions or changes in visual direction produced by the parts of the stimuli at the nodal point of the eye. Without a perception of distance, however, neither the retinal image nor the perceived 
directions associated with the parts of the retinal image alone can produce a linear perception of size or motion. Conversely, if a change in the linear perception of size or motion occurs with the perceived directions to the stimulus and the perceived position of the self held constant, the linear change in perceived size or motion must be attributed to a change in perceived distance. Thus, in Figure $1 \mathrm{~A}$, the linear change in the magnitude and direction of the perceived motion $W_{\mathrm{n}}^{\prime}$ and $W_{\mathrm{f}}^{\prime}$ for the same $\theta^{\prime}$ and $K^{\prime}$ is the result of the difference between $D_{\mathrm{n}}^{\prime}$ and $D_{\mathrm{f}}^{\prime}$. Similarly, the changes in perceived lateral (linear) motion of stimuli diagrammed in Figures 2, 4, 5, 6, 7, and 8 can be understood in terms of differences in perceived distance for a constant change in perceived direction and for a constant perceived motion of the observer's head. The research associated with Figure 8 clearly demonstrates the inability of retinal (or directional) changes independently of perceived distances to determine the perceived rotation, $\beta^{\prime}$, of the stimulus. This is clear, because $\beta^{\prime}$ is opposite in direction in Situations A and B, whereas the direction of relative retinal motion on the retina is the same for the two situations. It seems unlikely from the research associated with these demonstrations that linear perceptions of size, motion, shape, and orientation can be explained in any situation by perceptions determined exclusively by the size, motion, shape, or orientation of the retinal image.

A point of view seemingly at variance with the above comments reflects the observation that as distance information is increasingly reduced, either by removing cues of distance or by withdrawing attention from the stimulus, the perceptions of size and shape increasingly resemble the proximal stimulus. This has resulted in the postulation of different modes of perception. One mode involves a direct response to the retinal image and is not dependent on perceived distance. The other is capable of producing size and shape constancy or, more generally, is consistent with the requirements of the size-distance and shape-slant invariance hypotheses (Boring, 1946; Epstein \& Babler, 1989; Epstein \& Broota, 1986; Epstein \& Lovitts, 1985; Holway \& Boring, 1941; Mack, 1978; Rock, 1977, 1983). In terms of the theory presented in this paper, a seeming regression toward the proximal stimulus and, thus, toward independence from perceived distance as cue effectiveness is lessened either by cue reduction or by withdrawal of attention is misleading (Gogel \& DaSilva, 1987b; Gogel \& Sharkey, 1989). Instead of indicating independence from perceived distance, such results indicate only that the stimuli are perceived as displaced toward a constant perceived distance defined by the specific distance tendency and/or the equidistance tendency. The latter tendency refers to the finding that stimuli or parts of stimuli at different physical distances increasingly tend to appear at the same distance (equidistant) as information about their actual distances is increasingly reduced (Gogel, 1965). Whenever stimuli are perceived to be at the same distance from the observer (for whatever reason), regardless of their physical distances, they will appear to be essentially proportional in size and shape to the retinal image. But, that is simply a happenstance of their perceived equidistance.

A perceptual aspect of stimuli, termed phenomenal extensity, is described by Rock $(1977,1983)$ and Rock and McDermott (1964). Probably phenomenal extensity is similar to, or the same as, the perceived visual angle $\theta^{\prime}$. In the context of phenomenal geometry, it is important to be able to distinguish experimentally between the perception of visual angle, $\theta^{\prime}$, and the perception of linear size, $S^{\prime}$. A method for achieving this is suggested by Gogel and Eby (1990). The method involves the tactile adjustment of the lateral separation of two unseen posts that, as a pair, can be positioned at different distances from a stationary observer while always remaining in a frontoparallel plane. To measure $\theta^{\prime}$ (and probably phenomenal extensity), the observer is instructed to adjust the lateral position of the right post until it appears to be on the direction from the observer to the right edge of the stimulus. Similarly, the left post is adjusted laterally until it appears to be on the direction to the left edge of the stimulus. This is repeated with the pair of posts physically positioned at several different distances from the observer while remaining in a frontoparallel plane. If $\theta^{\prime}$ is being measured, the lateral separation between the posts resulting from their adjustment will increase with increases in the physical distance of the pair of posts from the observer. To measure $S^{\prime}$, the observer is instructed to separate the posts laterally until the distance between the posts is the same as the perceived lateral extent of the stimulus. If $S^{\prime}$ is being measured, the lateral separation of the posts should not systematically change with a change in the distance from the observer of the frontoparallel plane containing the posts. The angle obtained from the former adjustments is a measure of $\theta^{\prime}$. The constant lateral extent obtained from the latter adjustments is a measure of $S^{\prime}$.

\section{The Common Occurrence of Errors in Perceived Distance}

The theory of phenomenal geometry asserts that the perceived distance of a stimulus is essential to its location in phenomenal space. If it can be assumed in a situation that $\theta^{\prime}=\theta$ and $K^{\prime}=K$ in Equation 1 , it follows that an illusory lateral motion $\left(W^{\prime}\right)$ of the test object concomitant with the lateral motion of the head indicates that the perception of the distance of the test object is in error. This relationship can be used to identify the kinds of conditions in which errors in perceived distance are likely to be found. As indicated throughout this paper, the usual cues of distance or depth, such as convergence, binocular disparity, or perspective, can readily be manipulated to produce large errors in $D^{\prime}$ as signaled by substantial values of $W^{\prime}$. Also, errors in perceived distance can occur from less traditional distance or depth factors, such as the specific distance and equidistance tendencies, the distance at which the eyes are fixated, and possibly the distance to which attention is directed (Gogel, 1979a; Gogel \& Tietz, 1973, 1977). Several of these less tradi- 
tional factors can produce clear values of $W^{\prime}$ even for sit uations involving distances from the observer within which traditional cues are available and are considered to be quite effective. Two factors likely to be involved in producing errors in perceived distance under these conditions are the equidistance tendency combined with the distance at which the gaze is fixated. In a study by Gogel and Tietz (1977), a vertically moving test point at a constant distance from the observer was suspended in a visual field. The floor of the alley was covered with black cloth containing white polka dots. The observation was either binocular or monocular, and the observers fixated either the luminous test point or a fixation object resting on the alley floor and physically closer or farther than the distance of the test point. To measure $W^{\prime}$ in order to calculate $D^{\prime}$, measures of the apparent tilt $\left(\alpha^{\prime}\right)$ of the vertically moving test point, viewed with a lateral motion of the head, were obtained (see Figure $2 \mathrm{~B}$ for a similar procedure). The perceived distance of the test point was found to vary directly with changes in the distance of fixation for binocular as well as monocular observation. In other words, the nonfixated test point was perceptually displaced toward the perceived distance of the fixated object, and, in the case of binocular observation, this occurred despite the binocular disparity between the test point and fixation object or between the test point and the dots on the alley floor. Attending to the near or far object while fixating the test point had a similar but smaller effect. The robust effect of fixation can be attributed to a tendency (the equidistance tendency) for objects closer than or beyond the distance of the fixated object to appear displaced toward the distance of fixation. This result agrees with data obtained in a study by Wist and Summons (1976).

The effect of the combination of fixation distance and the equidistance tendency, illustrated in the above experiment, can explain the apparent concomitant motion $\left(\boldsymbol{W}^{\prime}\right)$ obtained in most situations in which the head is moved laterally while, for example, two fingers located at different physical distances are viewed. Usually, the nonfixated finger will appear to move more than the fixated finger. This is consistent with the presence of oculomotor cues appropriate to the distance of the fixated, but not the nonfixated, finger. The nonfixated finger will appear to move in the same direction as the motion of the head if it is physically more distant than the fixated finger, or opposite to the direction of the head motion if it is the physically closer finger. The values of $\boldsymbol{W}^{\prime}$ obtained in this case often are cited as an example of the effect of relative motion parallax. On the contrary, they represent a failure of relative motion parallax to determine the correct depth between the fingers. If it were completely effective, relative motion parallax would result in both fingers' appearing stationary and located at their physical distances as the head moved laterally. Also, although the illusory relative motions of the fingers produced in this manner are consistent in direction with the image motions on the eye, as has been discussed, they cannot be explained by only the retinal motions. Instead, the most likely cause is a decrease in the perceived depth between the fingers, which is produced by the equidistance tendency and augmented by the distance of fixation. Similar results can be obtained between other objects in the visual field when one of them is fixated. Results of this kind present difficulties for the theory of direct perception (Gibson, 1950, 1966), which assumes that the visual perception of the world is essentially veridical. In general, as the observer moves through space, nonfixated objects, although physically stationary, often appear to move. This illusory motion usually is disregarded by the observer, because the nonfixated objects are part of the surrounding visual field, which the observer knows to be physically stationary. However, if this surrounding field is absent, the illusory motion becomes indistinguishable from real motion (Peterson \& Shyi, 1988). But, whether or not the illusory motion is disregarded by the observer, the errors in perceived depth producing the illusory motion remain undiminished.

\section{Indirect Measures of Perceived Distance}

According to phenomenal geometry, errors in the perception of motions, orientations, sizes, or shapes, as the observer moves through the environment, reflect the presence of errors in the perception of distance, direction, or self-motion. The relation between these derived and basic characteristics can be measured by indirect procedures that significantly exclude cognitive processes from modifying the observer's responses. The use of perceived size to measure perceived distance, as expressed by Equation 5 or 6 of the SDIH, is one such indirect procedure. Unfortunately for this procedure, the response to size can be modified by a remembered standard, as is found in off-sized judgments, and it seems that this can occur even though plain geometrical shapes are used as test objects. An indirect procedure that is apt to be very efficient both in avoiding cognitive effects and in not introducing any modifications of the perceived distance to be measured is the null adjustment method used with the head motion procedure. It avoids the need to judge an extended $W^{\prime}$, because at the null setting $W^{\prime}=0$. Also, since at the null setting the pivot distance (Equation 2) equals the perceived distance of the test object, any motion parallax that might be introduced by the head motion should agree with the perceived distance of the test object in the absence of head motion. In principle, a variety of indirect measures applicable to measuring various aspects of phenomenal geometry are possible. For example, in Figure 6, the magnitude of $\beta^{\prime}$ is related to the magnitude of errors in the depth perceived between the two test points.

Indirect measures, to the degree that they are insensitive to cognitive effects, are useful, particularly when they are compared with more direct measures, in distinguishing experimentally between primary (perceptual) processes and secondary (cognitive) processes. The ability to make this distinction is important for the separation of the rules or laws that apply to these different domains. This distinction also is likely to be important for the evaluation of the development of spatial responses as organisms ma- 
ture. It is suggested that phenomenal geometry is a primary system that is available innately as soon as information regarding the three basic factors is capable of being used. Secondary processes that require experience can provide a supplement or correction to spatial responses that is needed because of limitations in the information provided by the primary system. Thus, secondary processes can contribute to the increased accuracy of spatial responses often characteristic of experienced observers.

\section{REFERENCES}

AMES, A., JR. (1952). The rotating trapezoid (Cont): Explanation of visual phenomena. In F. P. Kilpatrick (Ed.), Human behavior from the transactional point of view (pp. 75-86). Washington, DC: Office of Naval Research, Department of the Navy.

BIERSDORF, W. R. (1966). Convergence and apparent distance as correlates of size judgments at near distances. Journal of General Psychology, 75, 249-262.

BoRING, E. G. (1946). The perception of objects. American Journal of Physics, 14, 99-107.

Cutring, J. E. (1988). Affine distortions of pictorial space: Some predic tions for Goldstein (1987) that La Gournerie (1859) might have made. Journal of Experimental Psychology: Human Perception \& Performance, 14, 305-311.

COLTHEART, M. (1968). Size information as a factor in visual judgments of absolute distance under reduced conditions. Unpublished doctoral dissertation, University of Sydney, Sydney, Australia.

DAY, R. H., \& PARKS, T. E. (1989). To exorcize a ghost from the perceptual machine. In $\mathrm{M}$. Hershenson (Ed.), The moon illusion (pp. 343350). Hillsdale, NJ: Erlbaum.

DeREGOWSKI, J. B. (1980). Illusions, patterns, and pictures: A crosscultural perspective. New York: Academic Press.

DUNCAN, F. S. (1975). Kinetic art: On my psychokinematic objects. Leonardo 8, 97-101

Ellis, S. R., Smith, S., \& McGreevy, M. W. (1987). Distortions of perceived visual directions out of pictures. Perception \& Psychophysics, 42, 535-544.

EPSTEIN, W., \& BableR, T. (1989). Perception of slant-in-depth is automatic. Perception \& Psychophysics, 45, 31-33.

EpsteIN, W., \& BrootA, K. D. (1986). Automatic and attentional components in perception of size-at-a-distance. Perception \& Psycho physics, 40, 256-262.

EPStein, W., \& LANDAUER, A. A. (1969). Size and distance judgments under reduced conditions of viewing. Perception \& Psychophysics, 6, 269-272.

Epstein, W., \& LovitTs, B. E. (1985). Automatic and attentional components in perception of shape-at-a-slant. Journal of Experimental Psychology: Human Perception \& Performance, 11, 335-366.

FoleY, J. M. (1965). Visual space: A scale of perceived visual direction. Proceedings of the 73rd Annual Convention of the American Psychological Association, 1, 49-50.

FOLEY, J. M. (1968). Depth, size and distance in stereoscopic vision. Perception \& Psychophysics, 3, 265-274.

FOLEY, J. M. (1972). The size-distance relation and intrinsic geometry of visual space: Implications for processing. Vision Research, 12, 323-332.

GiBson, J. J. (1950). The perception of the visual world. Boston: Houghton Mifflin.

GiBson, J. J. (1966). The senses considered as perceptual systems. Boston: Houghton Mifflin.

Gillam, B. J. (1968). Perception of slant when perspective and stereopsis conflict: Experiments with aniseikonic lenses. Journal of Experimental Psychology, 78, 299-305.

GoGEL, W. C. (1954). Perception of the relative position of objects as a function of other objects in the field. Journal of Experimental Psychology, 47, 335-342.

GoGEL, W. C. (1965). Equidistance tendency and its consequences. Psychological Bulletin, 64, 153-163
GOGEL, W. C. (1969a). The effect of object familiarity on the perception of size and distance. Quarterly Joumal of Experimental Psychology, 21, 239-247.

GoGel, W. C. (1969b). The sensing of retinal size. Vision Research, 9, 1079-1094

Gogel, W. C. (1970). The adjacency principle and three dimensional visual illusions. In J. C. Baird (Ed.), Human space perception: Proceedings of the Dartmouth Conference. Psychonomic Monograph Supplement, 3(13, Whole No. 45), 153-169.

GOGEL, W. C. (1971). A validity of the size-distance invariance hypothesis with cue reduction. Perception \& Psychophysics, 9, 92-94.

GoGEL, W. C. (1976). An indirect method of measuring perceived distance from familiar size. Perception \& Psychophysics, 20, 419-429.

GoGEL, W. C. (1977). An indirect measure of perceived distance from oculomotor cues. Perception \& Psychophysics, 21, 3-11.

GoGEL, W. C. (1979a). The common occurrence of errors of perceived distance. Perception \& Psychophysics, 25, 2-11.

GoGEL, W. C. (1979b). Induced motion as a function of the speed of the inducing objects, measured by means of two methods. Perception, 8, 255-262.

GOGEL, W. C. (1980). The sensing of retinal motion. Perception \& Psychophysics, 28, 155-163

GoGEL, W. C. (1981a). Perceived depth is a necessary factor in apparent motion concomitant with head motion: A reply to Shebilske and Proffitt. Perception \& Psychophysics, 29, 173-177.

GoGEL, W. C. (1981b). The role of suggested size in distance responses. Perception \& Psychophysics, 30, 149-155.

GoGEL, W. C. (1982). Analysis of the perception of motion concomitant with a lateral motion of the head. Perception \& Psychophysics, 32, 241-250.

GOGEL, W. C. (1983). An illusory motion of a stationary target during head motion is unaffected by paradoxical retinal motion: A reply to Shebilske and Proffitt (1983). Perception \& Psychophysics, 34, $482-487$.

GOGEL, W. C. (1984). The role of perceptual interrelations in figural synthesis. In P. Dodwell \& T. Caelli (Eds.), Figural synthesis (pp. 3182). Hillsdale, NJ: Erlbaum.

Gogel, W. C., \& DaSilva, J. A. (1987a). Familiar size and the theory of off-sized perceptions. Perception \& Psychophysics, 41, 318-328.

Gogel, W. C., \& DASilva, J. A. (1987b). A two-process theory of the response to size and distance. Perception \& Psychophysics, 41, 220-238.

GOGEL, W. C., \& EBY, D. W. (1990). The perception of visual angle in optical change. Unpublished manuscript.

Gogel, W. C., \& HARKER, G. S. (1955). The effectiveness of size cues to relative distance as a function of lateral visual separation. Journal of Experimental Psychology, 50, 309-315.

Gogel, W. C., Loomis, J. M., Newman, N. J., \& Sharkey, T. J. (1985). Agreement between indirect measures of perceived distance. Perception \& Psychophysics, 37, 17-27.

GogeL, W. C., \& MERShoN, D. H. (1977). Local autonomy in visual space. Scandinavian Journal of Psychology, 18, 237-250.

Gogel, W. C., \& NEWTON, R. E. (1969). Perception of off-sized objects. Perception \& Psychophysics, 5, 7-9.

Gogel, W. C., \& Sharkey, T. J. (1989). Measuring attention using induced motion. Perception, 18, 303-320.

Gogel, W. C., \& STURM, R. D. (1971). Directional separation and the size cue to distance. Psychologische Forschung, 35, 57-80.

GOGEL, W. C., \& TiETZ, J. D. (1973). Absolute motion parallax and the specific distance tendency. Perception \& Psychophysics, 13, 284-292.

Gogel, W. C., \& TiETz, J. D. (1974). The effect of perceived distance on perceived movement. Perception \& Psychophysics, 16, 70-78.

GoGEL, W. C., \& TiETz, J. D. (1977). Eye fixation and attention as modifiers of perceived distance. Perceptual \& Motor Skills, 45, 343-362.

Gogel, W. C., \& TiETZ, J. D. (1979). A comparison of oculomotor and motion parallax cues of egocentric distance. Vision Research, 19, $1161-1170$.

GoGEL, W. C., \& TIETZ, J. D. (1990), Limitations of the role of cognitive factors in the perception of orientation in depth. Unpublished manuscript. 
GolDSTEIN, E. B. (1979). Rotation of objects in pictures viewed at an angle: Evidence for different properties of two types of pictorial space. Journal of Experimental Psychology: Human Perception \& Performance, 5, 78-87.

GoLDSTEIN, E. B. (1987). Spatial layout, orientation relative to the observer, and perceived projection in pictures viewed at an angle. Journal of Experimental Psychology: Human Perception \& Performance, 13, 256-266.

GolDSteIN, E. B. (1988). Geometry or not geometry? Perceived orientation and spatial layout in pictures viewed at an angle. Journal of Experimental Psychology: Human Perception \& Performance, 14, 312-314.

Gregory, R. L. (1968, November). Visual illusions. Scientific American, pp. 66-76.

Gregory, R. L. (1970). The intelligent eye. New York: McGraw-Hill.

HAY, J. C. (1968). Visual adaptation to an altered correlation between eye movement and hand movement. Science, 160, 429-430.

HAY, J. C., \& GoldSMITh, W. M. (1973). Space-time adaptation of visual position constancy. Journal of Experimental Psychology, 99. $1-9$.

Heinemann, E. G., Tulving, E., \& Nachmias, J. (1959). The effect of oculomotor adjustments on apparent size. American Journal of Psychology, 72, 32-45.

Holway, A. H., \& Boring, E. G. (1941). Determinants of apparent visual size with distance variant. American Journal of Psychology, 54, 21-37.

ItTELSON, W. H. (1952). The Ames demonstrations in perception (pp. 21-25). Princeton, NJ: Princeton University Press.

KomodA, M. K., \& ONo, H. (1974). Oculomotor adjustments and sizedistance perception. Perception \& Psychophysics, 15, 353-360.

Landauer, A. A., \& Epstein, W. (1969). Does retinal size have a unique correlate in perceived size? Perception \& Psychophysics, 6, 273-275.

Leibowitz, H. W. (1971). Sensory, learned, and cognitive mechanisms of size perception. Annals of the New York Academy of Sciences, 188, $47-62$.

LeIBOWITZ, H., \& Moore, D. (1966). Role of changes in accommodation and convergence in the perception of size. Journal of the Optical Society of America, 56, 1120-1123.

Leibowitz, H. W., Shinna, K., \& Hennessy, R. T. (1972). Oculomotor adjustments and size constancy. Perception \& Psychophysics, $12,497-500$.

Mack, A. (1978). Three modes of visual perception. In H. L. Pick, $\mathrm{Jr}$., \& E. Saltzman (Eds.). Modes of perceiving and processing information (pp. 171-186). Hillsdale, NJ: Erlbaum.

McCready, D. W., JR. (1965). Size-distance perception and accommodation-convergence micropsia: A critique. Vision Research $5,189-206$

MCCready, D. (1985). On size, distance, and visual angle perception. Perception \& Psychophysics, 37, 323-334.

McCready, D. (1986). Moon illusions redescribed. Perception \& Psychophysics, 39, 64-72.

MacCracken, P. J., Gogel, W. C., \& Blum, G. S. (1980). Effects of posthypnotic suggestion on perceived egocentric distance. Percep tion, 9, 561-568.

Ono, H., MUter, P., \& Mitson, L. (1974). Size-distance paradox with accommodative micropsia. Perception \& Psychophysics, 15, 301-307.

Peterson, M. A., \& Shyi, G. C.-W. (1988). The detection of real and apparent concomitant rotation in a three-dimensional cube: Implications for perceptual interactions. Perception \& Psychophysics, 44 $31-42$

Post, R. B., \& Leibowitz, H. W. (1982). The effect of convergence on the vestibulo-ocular reflex and implications for perceived movement. Vision Research, 22, 461-465.

Rock, I. (1977). In defense of unconscious inference. In W. Epstein (Ed.), Stability and constancy in visual perception: Mechanisms and processes (pp. 321-373). New York: Wiley.

Rock, I. (1983). The logic of perception. Cambridge, MA: MIT Press.

Rock, I., Hill, A. L., \& Fineman, M. (1968). Speed constancy as a function of size constancy. Perception \& Psychophysics, 4, 37-40.
Rock, I., \& MCDermotr, W. (1964). The perception of visual angle. Acta Psychologica, 22, 119-134.

Roelofs, C. O. (1935). Optische Lokalisation. Archiv fur Augenheilkunde, 109, 395-415.

SCHRIVER, W. (1925). Experimentelle Studien über stereoskopisches Sehen. Zeitschrift fur Psychologie, 96, 113-170.

ShebiLSKe, W. L., \& ProfFitT, D. R. (1981). The priority of perceived distance for perceiving motion has not been demonstrated: Critical comments on Gogel's "The sensing of retinal motion." Perception \& Psychophysics, 29, 170-172.

Shebilske, W. L., \& Proffitt, D. R. (1983). Paradoxical retinal motions during head movements: Apparent motion without equivalent apparent displacement. Perception \& Psychophysics, 34, 476-481.

Swanston, M. T., \& Gogel, W. C. (1986). Perceived size and motion in depth from optical expansion. Perception \& Psychophysics, 39, 309-326.

TIETZ, J. D., \& Gogel, W. C. (1978). Adaptation to apparent concomitant motion in the absence of physical or retinal motion. Bulletin of the Psychonomic Society, 12, 1-4.

VAN DER MEER, H. C. (1979). Interrelation of the effects of binocular disparity and perspective cues on judgments of depth and height. Perception \& Psychophysics, 26, 481-488.

von Holst, E., Mittelstaedt, H. (1950). Das Reafferenz-Prinzip. Die Naturwissenschaften, 20, 464-476.

Wallach, H. (1985, May). Perceiving a stable environment. Scientific American, pp. 118-124.

WaLLACH, H. (1987). Perceiving a stable environment when one moves. Annual Review of Psychology, 38, 1-27.

Wallach, H., Bacon, J., \& Schulman, P. (1978). Adaptation in motion perception: Alteration of induced motion. Perception \& Psychophysics, 24, 509-514.

Wallach, H., FloOr, L. (1970). On the relation of adaptation to field displacement during head movements to the constancy of visual direction. Perception \& Psychophysics, 8, 95-98.

WALLACH, H., \& FREY, K. J. (1969). Adaptation in the constancy of visual direction measured by a one-trial method. Perception \& Psychophysics, 5, 249-252.

Wist, E. R., Diener, H. C. , \& Dichgans, J. (1976). Motion constancy dependent upon perceived distance and the spatial frequency of the stimulus pattern. Perception \& Psychophysics, 19, 485-491.

Wist, E. R., Diener, H. C., Dichgans, J., \& Brandt, Th. (1975). Perceived distance and the perceived speed of self-motion: Linear vs. angular velocity? Perception \& Psychophysics, 17, 549-554

Wist, E. R., \& Summons, E. (1976). Spatial and fixation conditions affecting the temporal course of changes in perceived relative distance. Psychological Research, 39, 99-112.

\section{NOTES}

1. A paper concerning evidence relevant to Figure 1 was presented at the 27th Annual Meeting of the Psychonomic Society, New Orleans, LA, November 1986.

2. Often deviations from the strict form of the SDIH are indicated by values different from unity of a constant of proportionality between $S^{\prime} / D^{\prime}$ and $\tan \theta^{\prime}$ (derived from the responses shown in Figure 9) or, in the case of Equation 6 , between $S^{\prime} / 2 D^{\prime}$ and $\tan \left(\theta^{\prime} / 2\right)$ (derived from Figure 1C). In Figure 9, this constant is unity in A, is greater than unity in $\mathrm{B}$, and is less than unity in C. It also is possible to express this deviation in terms of a power function in which either the constant of proportionality or the exponent differs from unity, or in which both of them do (Foley, 1968; Gogel, 1971).

3. It is equally appropriate to call the ratio $S_{\mathrm{t}}^{\prime} / S_{\mathrm{s}}$ either an off-sized judgment or an off-sized perception, since it involves both a memory $S_{\mathrm{s}}$ and a perception $S_{\mathrm{t}}^{\prime}$ (see Gogel, 1981b, note 1).

(Manuscript received July 17, 1989; revision accepted for publication March 21, 1990.) 